\title{
Genomic Landscape of Transcriptional and Epigenetic Dysregulation in Early Onset Polyglutamine Disease
}

\author{
Luis M. Valor, ${ }^{\star}$ Deisy Guiretti, ${ }^{\star}$ Jose P. Lopez-Atalaya, ${ }^{\star}$ and Angel Barco \\ Instituto de Neurociencias de Alicante (Universidad Miguel Hernández-Consejo Superior de Investigaciones Científicas), Sant Joan d’Alacant, 03550, \\ Alicante, Spain
}

Transcriptional dysregulation is an important early feature of polyglutamine diseases. One of its proposed causes is defective neuronal histone acetylation, but important aspects of this hypothesis, such as the precise genomic topography of acetylation deficits and the relationship between transcriptional and acetylation alterations at the whole-genome level, remain unknown. The new techniques for the mapping of histone post-translational modifications at genomic scale enable such global analyses and are challenging some assumptions about the role of specific histone modifications in gene expression. We examined here the genome-wide correlation of histone acetylation and gene expression defects in a mouse model of early onset Huntington's disease. Our analyses identified hundreds of loci that were hypoacetylated for H3K9,14 and H4K12 in the chromatin of these mice. Surprisingly, few genes with altered transcript levels in mutant mice showed significant changes in these acetylation marks and vice versa. Our screen, however, identified a subset of genes in which $\mathrm{H} 3 \mathrm{~K} 9,14$ deacetylation and transcriptional dysregulation concur. Genes in this group were consistently affected in different brain areas, mouse models, and tissue from patients, which suggests a role in the etiology of this pathology. Overall, the combination of histone acetylation and gene expression screenings demonstrates that histone deacetylation and transcriptional dysregulation are two early, largely independent, manifestations of polyglutamine disease and suggests that additional epigenetic marks or mechanisms are required for explaining the full range of transcriptional alterations associated with this disorder.

\section{Introduction}

Polyglutamine (polyQ) diseases are autosomal dominant neurodegenerative disorders caused by an aberrant expansion of CAG triplet-repeats in neuronal genes (Orr and Zoghbi, 2007). In the case of Huntington's disease (HD), this expansion takes place in the huntingtin (HTT) gene (MacDonald et al., 1993). HD is usually diagnosed in adulthood on the basis of characteristic symptoms, such as involuntary movement, changes in character, and cognitive deficits (Zuccato et al., 2010). Previous studies have indicated that transcriptional dysregulation is an important early feature of HD and other polyQ diseases (Cha, 2000; Bowles et al., 2012; Seredenina and Luthi-Carter, 2012). One of the proposed

Received Feb. 13, 2013; revised May 8, 2013; accepted May 20, 2013.

Author contributions: L.M.V. and A.B. designed research; L.M.V., D.G., and J.P.L.-A. performed research; L.M.V., D.G., J.P.L.-A., and A.B. analyzed data; L.M.V. and A.B. wrote the paper.

This work was supported by the Spanish Ministry of Science and Innovation (Grants SAF2008-03194-E (part of the coordinated ERA-Net NEURON project Epitherapy) and SAF2011-22855 to A.B., SAF2011-22506 to L.M.V., and CSD2007-00023) and grants from the Generalitat Valenciana (Prometeo/2012/005), Fundació La Marató de TV3 (063510) and Fundació Gent per Gent. We thank the support of Asociación Valenciana de Enfermedad de Huntington (AVAEH). L.M.V.'s research is supported by a Ramón y Cajal contract from the Spanish Ministry of Economy and Competiveness. D.G. and J.P.L.-A. hold, respectively, a predoctoral fellowship (JAE-pre) and a postdoctoral contract (JAE-doc) from the Program "Junta para la Ampliación de Estudios" cofunded by the Fondo Social Europeo (FSE). We thank Santiago Canals and Jesús Pacheco for their help in the acquisition and analysis of MRI data, Román Olivares for excellent technical assistance in the maintenance of the mouse colony, and Eva Benito for the help with initial bioinformatics analyses.

The authors declare no competing financial interests.

*L.M.V., D.G., and J.P.L.-A contributed equally to this work.

Correspondence should be addressed to either Angel Barco or Luis M. Valor, Instituto de Neurociencias de Alicante, Campus de San Juan, Apartado 18, Sant Joan d'Alacant 03550, Alicante, Spain. E-mail: abarco@umh.es or Imv@umh.es.

DOI:10.1523/JNEUROSCI.0670-13.2013

Copyright $\odot 2013$ the authors $\quad 0270-6474 / 13 / 3310471-12 \$ 15.00 / 0$ causes of this dysregulation is defective neuronal histone acetylation (Saha and Pahan, 2006; Stack et al., 2007; Valor et al., 2013) but different aspects of this hypothesis remain controversial and require further investigation. Thus, not all studies on HD animal models have confirmed the deacetylation of histones in bulk chromatin assays (Hockly et al., 2002; Sadri-Vakili et al., 2007; Klevytska et al., 2010; McFarland et al., 2012) and the genomic topography of the possible acetylation deficits remains unknown. To address these questions, we chose the transgenic mouse strain N171HD82Q (subsequently referred as HD82Q), which expresses a truncated version of mutant $\mathrm{Htt}(\mathrm{mHtt})$ bearing an 82-residue long polyQ tract and reproduces many features of $\mathrm{HD}$, including progressive weight loss and tremors, motor impairment, cognitive deficits, and premature death (Schilling et al., 1999).

We present here the first parallel genome-wide analysis of transcriptional and histone acetylation deficits in a polyQ disease model. The combination of ChIPseq and microarray technologies supported the hypothesis that transcriptional and epigenetic dysregulation, particularly aberrant acetylation of neuronal chromatin, are important early features of $\mathrm{HD}$, and identified the sites of epigenetic and transcriptional dysregulation with nucleosome resolution. The comparison of these two differential screens demonstrated that most local histone acetylation deficits were not associated with transcriptional dysregulation except for a subset of genes that showed both reduced transcript levels and deficits in $\mathrm{H} 3 \mathrm{~K} 9,14$ acetylation at the transcription start site (TSS). Genes in this group were consistently altered in different brain areas, mouse models, and in transcriptomic data derived from human patients, and therefore, represent suitable candidates as progression biomarkers or therapeutic targets for this devastating disease. 


\section{Materials and Methods}

Animals. The transgenic strain PrP-htt-N171-82Q (Schilling et al., 1999) was acquired from Jackson Laboratories (stock No. 003627) and maintained in a DBA and C57BL/6J mixed background (50:50) because the viability of the strain is compromised in a pure $\mathrm{C} 57 \mathrm{BL} / 6 \mathrm{~J}$ background. In both the microarray-based and ChIPseq-based differential screenings, tissue from several animals was pooled together to minimize the potential genetic variability that could result from this mixed background. Sodium butyrate was administered as previously described (Valor et al., 2011); mice were intraperitoneally injected with vehicle (PBS) or sodium butyrate $(1.2 \mathrm{mg} / \mathrm{Kg})$ and killed $30 \mathrm{~min}$ later. Experimental protocols were consistent with European regulations and approved by the Institutional Animal Care and Use Committee.

Behavioral testing. For all behavioral tasks, we compared HD82Q animals and wild-type littermates of the indicated age. RotaRod and Morris water maze tasks were performed as described previously (Valor et al., 2011). Grip strength values are the average of six measures in the Grip Strength Meter (Ugo Basile).

MRI analysis. For magnetic resonance imaging (MRI), mice were anesthetized, perfused with $4 \%$ paraformaldehyde, and decapitated. The whole head was postfixed overnight and included in agarose before data acquisition as reported (Lopez-Atalaya et al., 2011). Length and volume measurements were performed using ImageJ software.

Histological and Western-blot analyses. Nissl staining, immunohistochemistry, and Western-blot analyses were performed as previously described (Lopez de Armentia et al., 2007; Sanchis-Segura et al., 2009). Cell counting and signal intensities quantification were performed using ImageJ software. The following antibodies were used: acetyl-histone antibodies specific for the panacetylated forms of H2A (K5, K9), H2B (K5, $\mathrm{K} 12, \mathrm{~K} 15, \mathrm{~K} 20), \mathrm{H} 3$ (K9, K14), and $\mathrm{H} 4$ (K5, K8, K12, K16) produced in our laboratory (Sanchis-Segura et al., 2009); $\alpha$-Huntingtin, clone mEM48 (MAB5374), $\alpha$-AcH3K9,14 (06-599), $\alpha$-H2B (07-371), $\alpha$-H3 (05-499), $\alpha$-NeuN (MAB377) from Millipore; $\alpha$-AcH4K12 (ab46983) from Abcam; $\alpha$-GFAP (G9269), $\alpha$-MAP2 (M4403), $\alpha$ - $\beta$-actin (F5441), and biotinylated and HRP-conjugated secondary antibodies from Sigma-Aldrich Química S.A., and Alexa Fluor 594 secondary antibody (A-21209) from Invitrogen.

RNA extraction, RT-qPCR, and microarray analyses. Quantitative RTPCR (RT-qPCR) assays were performed as previously described (Valor et al., 2011). Each independent sample was assayed in duplicate and normalized using glyceraldehyde 3-phosphate dehydrogenase (GAPDH) levels. All primer sequences are available upon request. For microarray experiments, RNA from 3 to 4 mice of the same age, sex, and genotype were pooled and cleaned up using the RNeasy Mini Kit (Qiagen). Three independent pooled samples per genotype and brain area were hybridized to Mouse Gene 1.0 ST expression arrays (Affymetrix). All the mice (mutant and controls) used in the 10-week analysis were males, whereas all the mice used in the 20 -week analysis were females. We did not observe apparent sex differences in histopathology, premature death, and gene-specific RT-qPCR assays. Microarray data were background corrected, normalized, summarized, and statistically analyzed using $\mathrm{R}$ and Bioconductor (Gentleman et al., 2004). Mouse Gene 1.0 ST arrays were read using oligo package, using RMA algorithm as normalization method. The limma package (Smyth, 2005) was used for extracting statistically significant changes between HD82Q and control samples (moderated $t$ tests). Fold-change $>1.25$ and adjusted $P<0.05$ were used as filters. These files can be downloaded from the Gene Expression Omnibus (GEO) database using the accession number GSE44855. Striatal profiles were obtained from the datasets GSE9803 and GSE9804 corresponding to 12 -week-old R6/2 mice (Kuhn et al., 2007) and processed in a similar manner than $\mathrm{HD} 82 \mathrm{Q}$ arrays except for the use of the affy package to read the CEL files. Gene expression changes in caudate nucleus of postmortem brain from HD patients were obtained from Hodges et al. (2006). The same reported $P$ value threshold was used $(p<0.001)$ but additionally we applied a fold-change (FC) filter $(>1.25)$ to minimize the impact of very weak changes in our subsequent analyses.

ChIP assays and ChIPseq analysis. Chromatin immunoprecipitation (ChIP) was performed as described previously (Lopez-Atalaya et al.,
2011). ChIP-qPCR validation of candidate genes and ChIPseq experiments were performed in independent cohorts of animals. For conventional ChIP assays, we used dissected tissue from two mice for the hippocampal samples and from a single animal for the cerebellar samples. qPCR on IP chromatin was performed as described for RT-qPCR using specific primers close to the TSS. All primer sequences are available upon request. Because initial two-way ANOVA analyses did not reveal significant age effects or age-genotype interaction, we pooled the data corresponding to 10- and 20-week-old animals. For the ChIPseq-based screen, we generated four deeply sequenced libraries after IP of hippocampal chromatin (pooled crude chromatin extracts from the hippocampi of 16 10-week-old male mice) using antibodies against AcH3K9,14 (06-599 from Millipore) and AcH4K12 (ab46983 from Abcam). Libraries were prepared using indexed adapters following standard Illumina library preparation kits and protocols. High-throughput sequencing was performed using a HiSeq-2000 apparatus (Illumina) with 50 TruSeq SBS v3 sequencing kit following the manufacturer's instructions. Indexed reads were demultiplexed into individual samples, filtered for low-quality reads and adaptor sequences. Fifty base-pair long single-read datasets were obtained for AcH3K9,14 (wt and HD82Q mice), AcH4K12 (wt and HD82Q mice), input (wt mice), and preimmune serum (wt mice and HD82Q mice). To achieve sufficient genome depth coverage to identify post-translational chromatin modifications, the depth of the sequencing run was between 8.4 and $14.5 \times 10^{6}$ reads per sample $\left(\mathrm{AcH} 3 \mathrm{~K} 9,14_{\mathrm{WT}}: 13,867,710 ; \mathrm{AcH}_{4 \mathrm{~K} 12}{ }_{\mathrm{WT}}\right.$ : 14,187,515; AcH3K9,14 HD82Q $_{1}$ 9,053,780; AcH4K12 $_{\mathrm{HD} 82 \mathrm{Q}}$ : 9,935,242; input sample: 7,904,594; IgG condition: 9,220,090). A saturation analysis indicated that the depth of sequencing was sufficient for reliable detection of histone acetylation peaks in our samples (data not shown). Reads were aligned to the NCBI-M37/mm9 reference genome using BWA ( $\mathrm{Li}$ and Durbin, 2010), and BAM files were parsed using the SAMTOOLS (Li et al., 2009) to extract uniquely mapped reads (AcH3K9,14 ${ }_{\mathrm{WT}}$ : 88\%; AcH4K12 ${ }_{\mathrm{WT}}: 86 \%$; AcH3K9, $14_{\mathrm{HD} 82 \mathrm{Q}}: 89 \%$; $\mathrm{AcH} 4 \mathrm{~K} 12_{\mathrm{HD} 82 \mathrm{Q}}: 85 \%$; input sample: $80 \%$; IgG condition: $80 \%$ ). SICER algorithm (Zang et al., 2009) was used to extract acetylation-enriched chromatin regions. To further increase the depth of coverage and to exclude false positive enrichedregions due to eventual local deficits of coverage in the control dataset, acetylation-enriched regions were identified using pooled input and IgG libraries as control library. SICER parameters for island identification were as follows: redundancy threshold $=100$, window size $=200$, gap size $=2(\mathrm{AcH} 3 \mathrm{~K} 9, \mathrm{~K} 14)(3$ for AcH4K12), fragment size $=150$, effective genome fraction $=0.77$, FDR $($ enriched islands $)=10^{-8}$. For the differential screen, we set a threshold of FDR adjusted $p<10^{-3}$ to identify the most reliably changed histone acetylation islands. The large islands at the Prnp promoter corresponding to the detection of the transgene were not considered in subsequent analyses. Overlap and annotation of significantly enriched islands was done with ChipPeakAnno (Zhu et al., 2010). RefSeq gene annotations were obtained from the University of California at Santa Cruz (UCSC) Genome Bioinformatics website. Seqmonk and Integrative Genomics Viewer (IGV; Robinson et al., 2011) were used for data visualization and coverage snapshots at discrete loci. Wig files containing the coverage data (normalized read density per million bp; RPM) across the enriched regions for the two acetylated histones were obtained using IGV Tools. Read length was extended $200 \mathrm{bp}$. The files were then normalized to the size of the dataset using Wigreader. The high-throughput sequencing data generated in this study has been deposited at NCBI's GEO and can be consulted through the accession number GSE44855.

Meta-analysis of microarray and ChIPseq data. $\log _{2}$ fold-change values from hippocampal microarray and ChIPseq data were directly correlated. We also performed a Pearson correlation analysis using $P$ values that did not reveal any significant association. In those cases in which more than one island were associated with the same gene, fold-changes were averaged with the assumption that all the islands similarly contribute to gene expression. As an alternative to average, the nearest island to the gene was tested without further improvement in the correlation coefficients. In the $\chi^{2}$-square tests the expression data corresponding to the whole array was first ranked according to the $P$ values of TC IDs (MG 1.0 ST) or probesets (MG 430, HU133A, and B). The rank of the TC IDs/ probesets corresponding to Exp-AcH3 genes was determined and $\chi^{2}$ 
A

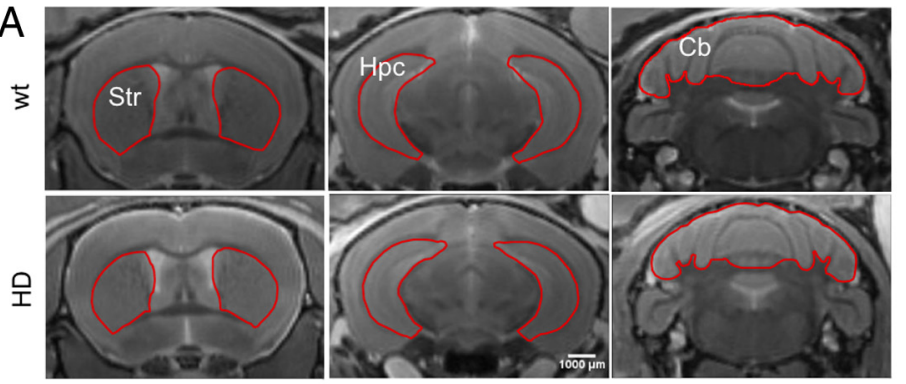

$B$

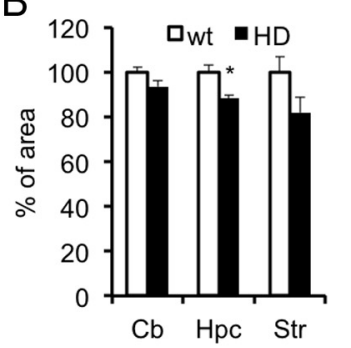

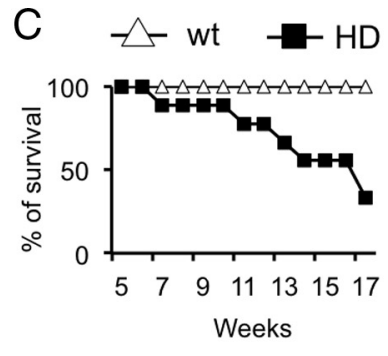

$\mathrm{D}$

E

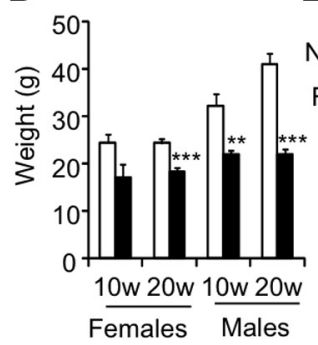

E
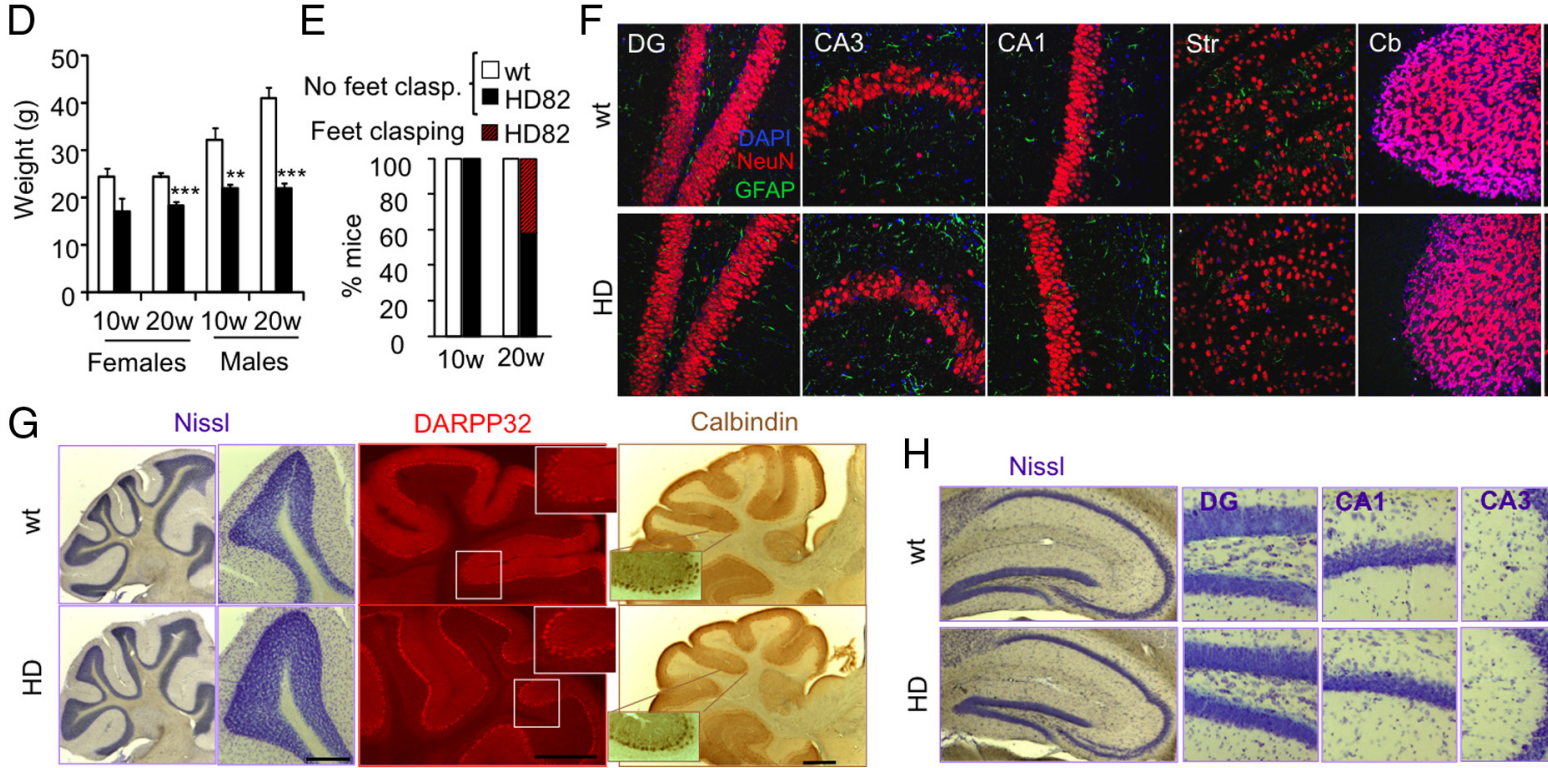

Ctx

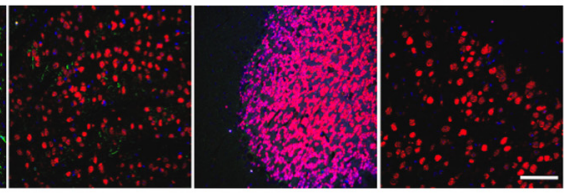

$\mathrm{H} \quad$ Nissl

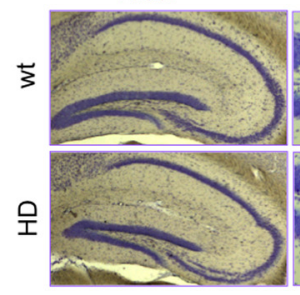

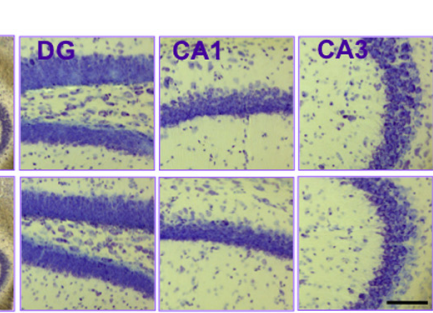

MAP2

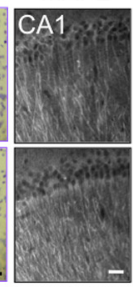

Figure 1. HD82Q mice show neuropathological traits in the absence of neurodegeneration. $\boldsymbol{A}$, Representative MRI images showing the striatum (Str), hippocampus (Hpc), and cerebellum (Cb) of a 20-week-old HD82Q mouse and a control littermate. Red line denotes the area considered for quantification. $\boldsymbol{B}$, Volume quantification of these brain areas (three animals per genotype). Mutant mice had smaller brains. However, morphometric ratios were maintained between different brain regions and there was no apparent enlargement of lateral ventricles. Data are represented as mean $\pm \mathrm{SEM}^{*} p<0.05$, Student's t test HD versus wt. C, HD82Q (HD) mice had a short life span. Premature death was occasionally observed at early symptomatic stages ( $n=9$ for each genotype). $\boldsymbol{D}, \mathrm{HD} 82 \mathrm{Q}$ mice did not gain weight in the same progression that control littermates. This phenotype was especially severe in males. $\boldsymbol{E}$, Percentage of 10 - and 20 -week-0ld mice showing feet clasping during 1 min tail suspension test. $\boldsymbol{F}$, Double immunostaining of brain sections of 12-week-old HD82Q mice and control littermates with a marker for neurons (NeuN) and glial cells (GFAP) showed no significant difference in the number of either cell type, indicating that there is neither neuronal cell loss nor gliosis. Scale bar, $10 \mu \mathrm{m}$. G, Cerebellar morphology in 12 -week-old HD82Q mice and control littermates were undistinguishable; the quantification of layers thickness did not reveal any significant change (data not shown). Left, Nissl staining. Right, Immunostaining of cerebellar sections with the cerebellar markers DARPP32 and calbindin. Scale bars: Nissl, $200 \mu \mathrm{m}$; DARPP2 and calbindin, $500 \mu \mathrm{m}$. $\boldsymbol{H}$, Hippocampal morphology in 12 -week-old HD820 mice and control littermates were undistinguishable; the quantification of layers thickness did not reveal any significant change (data not shown). Left, Nissl staining. Right, Immunostaining with the neuronal marker MAP2. Scale bars: Nissl, $100 \mu \mathrm{m} ;$ DARPP2 and MAP2, $25 \mu \mathrm{m}$.

values were calculated related to a random distribution. For Gene Ontology (GO) terms enrichment, we used the functional annotation tools implemented in DAVID (Huang et al., 2009) using the whole mouse genome as background list. Only enrichments with a $P$-value $<0.05$ were considered. Significant GO terms retrieved from different gene expression datasets were compared using Venny software (Oliveros, 2007); redundant (highly related but nonexactly matched) terms were not considered in the analysis. The resulting GO terms were manually collapsed. To predict enrichment of transcription factor binding sites (TFBS), Pscan software was used to scan motifs from the Jaspar database in promoter regions (-950/+50; Zambelli et al., 2009). As datasets we used the lists of differentially expressed and differentially acetylated genes at their TSS. For Spearman correlation, all the Jaspar motifs (130) were ranked according to their Z-score, independently of their significance, for each dataset. Only enrichments with $P<0.05$ were considered significant.

\section{Results}

HD82Q mice show neuropathological traits in the absence of neurodegeneration

HD82Q mice exhibit slight brain atrophy but grossly normal anatomy (Fig. $1 A, B$ ). Despite their premature death (Fig. $1 C$ ), severe weight loss (Fig. 1D), and motor dysfunction (Fig. 1E), no apparent neurodegeneration or active gliosis were observed even in the late stages of the disease (Fig. $1 F-H$; Schilling et al., 1999; Klevytska et al., 2010). We reasoned that the dissociation between neuronal malfunction and death could allow us to investigate transcriptional and epigenetic dysregulation without the confounding factor of changes in the cellular composition of the tissue. Detailed histological analysis of $\mathrm{mHtt}$ aggregates identified the cerebellum and the hippocampus as the two main brain areas of transgene expression (Fig. 2A,B). In agreement with this observation, processes that depend on proper functioning of these regions, such as motor performance in the rotarod task (Fig. 2C), grip control (Fig. 2D), and spatial learning in the water maze (Fig. $2 E-G$ ), were severely affected in HD82Q mice (Fig. 2 , see legend for additional detail). Importantly, cerebellar and hippocampal functions are also altered in HD patients (Snowden et al., 2002; Seneca et al., 2004). We focused our subsequent analyses on these two tissues.

Severe transcriptional dysregulation in $\mathrm{mHtt}$-expressing tissues To investigate genome-wide transcriptional dysregulation in HD82Q mice, we performed microarray analysis on hippocam- 


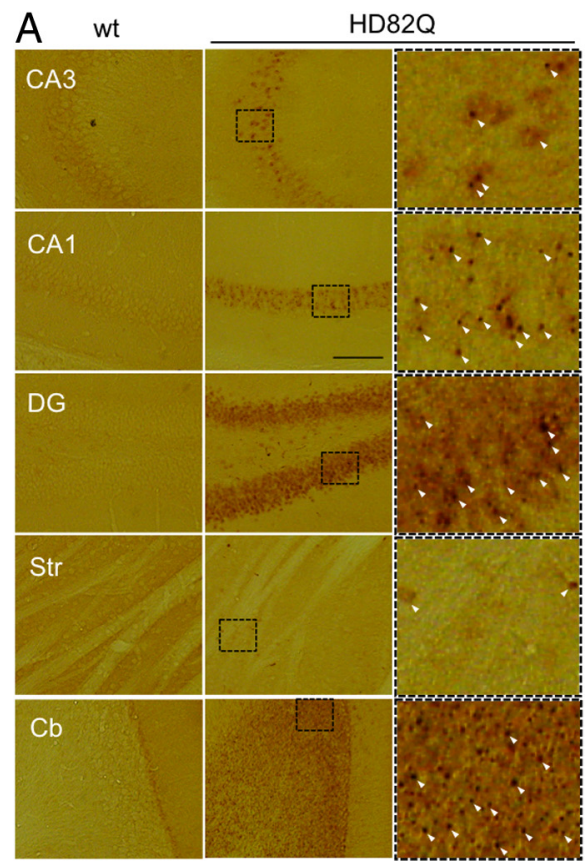

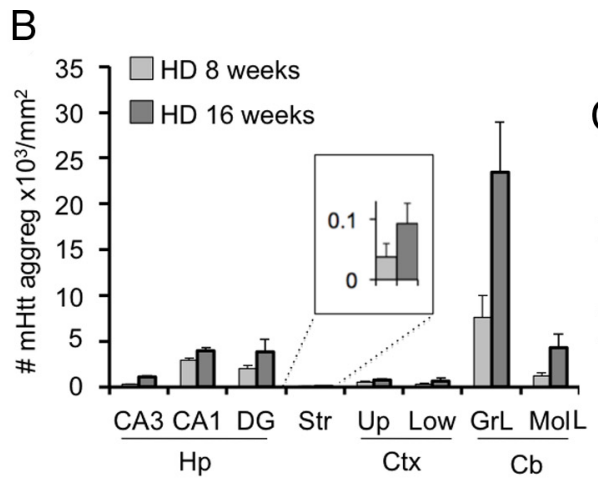
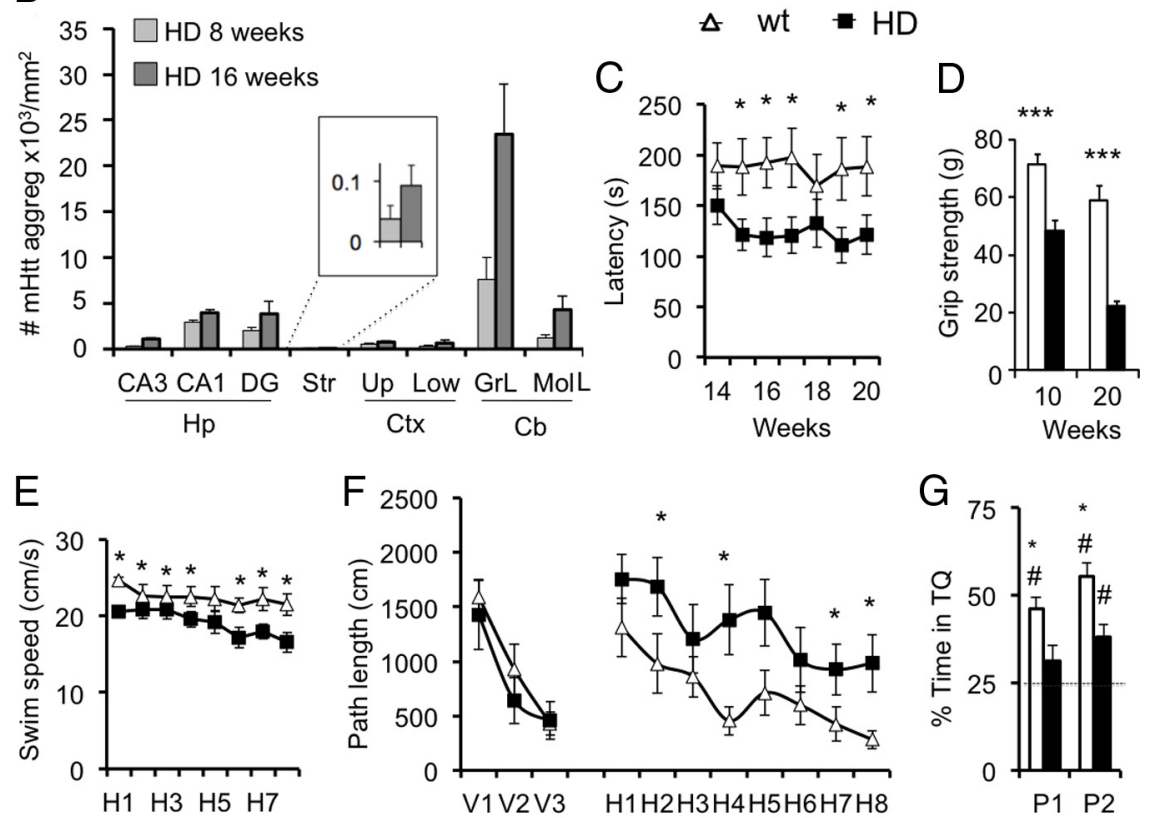

Figure 2. Impaired cerebellar and hippocampal function in HD82Q mice. $A$, Transgene expression in HD82Q mice. Strong mHtt immunoreactivity was detected in hippocampus and cerebellum of HD82Q mice. Aggregates were also detected in lower amount in the cortex and striatum of HD82Q mice, but were absent in sections from wt littermates. Representative images corresponding to the CA1, CA3, and dentate gyrus (DG) subfields in the hippocampus, striatum (Str), and cerebellum (Cb) of 16-week-old HD82Q mice are shown. Insets in HD82Q show higher-magnification images of $\mathrm{mHtt}$ aggregates labeled with white arrowheads. Scale bar, $100 \mu \mathrm{m}$. B, Quantification of $\mathrm{mHtt}$ immunoreactivity in brain sections of 8-and 16-week-0ld HD820 mice. The strongest expressions were detected in the hippocampus and cerebellum, followed by the cortex and striatum ( $n=3$ per genotype). Hp, Hippocampus; Cb, cerebellum; Str, striatum; Up, cortical upper layers; Low, cortical lower layers; GrL, granular layer; MoL, molecular layer. Note that the presence of mHtt aggregates in the cerebellum was 100 -fold higher than that in the striatum or cortex. This result is in agreement with images presented in the original publication describing this strain (Schilling et al., 1999). C, Mutant mice slipped from the rod earlier than control littermates in an accelerated speed rotarod task ( $n=10$ for wt, $n=11$ for HD82Q). The weak $\mathrm{mHtt}$ staining observed in striatal tissue suggests that the motor deficits in HD82Q mice may be largely cerebellum-dependent. $\boldsymbol{D}, 10$ - and 20 -week-old HD82Q mice showed a significant reduction of grip strength. $\boldsymbol{E}-\mathbf{G}, 3$-month-old HD82Q mice were severely impaired in the Morris water maze task ( $n=11$ for wt, $n=8$ for HD82Q). Mutant mice showed reduced swimming speed $(\boldsymbol{E})$ and longer path lengths to reach the platform in the hidden version of the task (F: H1-H8), but normal learning in the visible platform task (F: V1-V3). Mutant mice also performed worse than wild-type littermates in the probe trials in day 5 (G: P1) and 9 (G: P2). These results suggest the existence of spatial learning defects in addition to the motor impairment, although these two defects are difficult to dissociate. Data are presented as mean \pm SEM ${ }^{*} p<0.05 ;{ }^{* *} p<0.01 ;{ }^{* * *} p<0.001$ (Student's $t$ test) for differences between genotypes. $\#, p<0.05$ (Student's $t$ test) for comparison with random performance.

pal RNA using Affymetrix Mouse Gene 1.0 ST arrays at two different stages of disease: early symptomatic (10 weeks old) and terminal (20 weeks old; Fig. 3A). Differential gene profiling analysis identified 436 transcript cluster IDs (TC IDs), corresponding to 405 annotated genes, that showed a significant genotype effect (FC $>1.25$, adjusted $p<0.05$ ). The profiles of transcriptional dysregulation in HD82Q mice were very similar at the two investigated time points, as shown both in the hierarchical clustering (Fig. 3B) and correlation plot (Fig. 3C) analyses. Pairwise contrast tests retrieved the lists of TC IDs significantly altered at specific time points and confirmed the early onset of most transcriptional deficits and their moderate progression with age (Fig. $3 C, D)$. No TC IDs showed a significant interaction between genotype and age. The progression of the pathology in terms of gene profiling was reflected in a modest increase in the severity of the changes $\left(\mathrm{FC}_{\text {Down TCIDs }}: 0.71 \pm 0.01\right.$ in 10 -week-old mice vs $0.67 \pm 0.01$ in 20 -week-old mice, $p=0.005 ;$ FC $_{\text {Up TCIDs }}: 1.27 \pm$ 0.02 vs $1.52 \pm 0.02, p=6.5 \times 10^{-13}$ ) and a larger number of affected TC IDs (two- and eightfold increase for down- and upregulations, respectively). These results indicate that $\mathrm{mHtt}$ expression is initially strongly associated with impaired gene expression (up/ down ratio $=0.09$ ) and later leads to numerous gene upregulations (up/down ratio $=0.43$ ), which might reflect the emergence of a homeostatic or defense response to polyQ pathology.

To extend our transcriptomic analysis to a different tissue, we also performed microarray analysis with RNA from cerebellar tissue of the same 10-week-old animals. As shown in Figure $2 B$, this tissue presented the highest density of $\mathrm{mHtt}$ aggregates in the brain of HD82Q mice. The comparison between control and HD82Q samples detected 1624 TC IDs corresponding to 1413 annotated genes $(\mathrm{FC}>1.25$, adjusted $p<0.05)$. These results indicate that the extension of transcriptional dysregulation correlates with the abundance of $\mathrm{mHtt}$ aggregates and suggest that the cerebellum may be more sensitive to polyQ pathology than the hippocampus (Fig. 3E). Only 111 genes were consistently affected in both tissues, indicating that a majority of mHtt transcriptional targets are tissue specific. Among the affected transcripts in both tissues, we found relevant genes known to be altered in HD (Seredenina and Luthi-Carter, 2012) like the ones encoding the neuropeptide enkephalin (Penk), subunits of glutamate (Grm2) and GABA receptors (Gabrd), and the GTPbinding protein Rasd2 (also known as Rhes). Among the upregulated transcripts we found Nfya, which encodes for a subunit of the transcription factor NF-Y that is sequestered in $\mathrm{mHtt}$ aggregates (Yamanaka et al., 2008). As a positive control for our screen, the analysis of individual probesets confirmed the overexpression of $H t t$ exon 1, which is part of the transgene construct, in all HD82Q samples (Fig. $3 F$ ).

We next examined the expression of a number of candidate genes, both common and region-specific, at different stages of the pathology, from presymptomatic to terminal mice through RTqPCR assays using independent samples (Fig. 3G). Our assays 


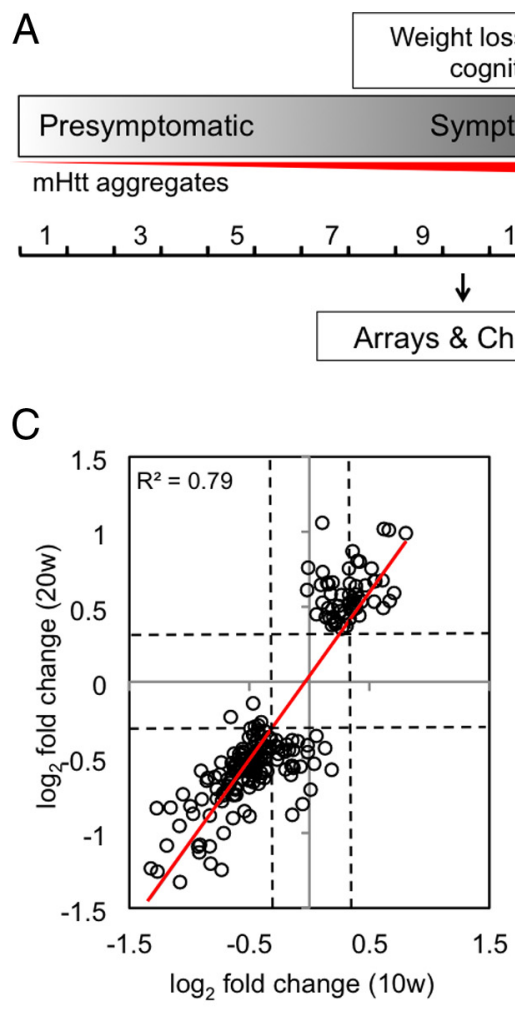

loss, tremors, motor and

Symptomatic

\section{Terminal}

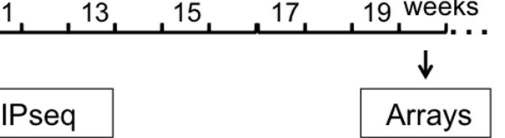

G

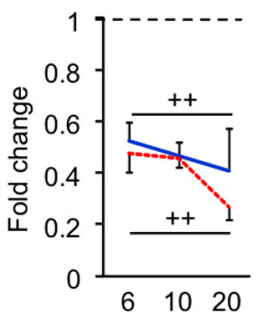

$\mathrm{D}$

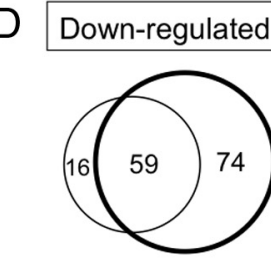

E

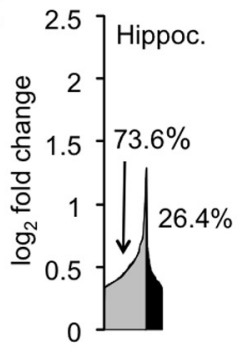

Up-regulated

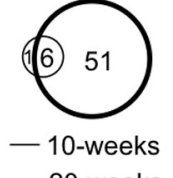

- 20-weeks

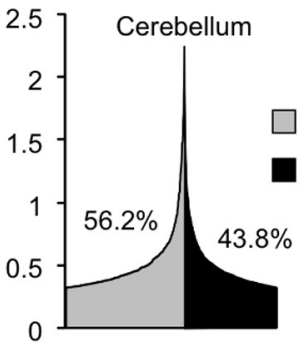

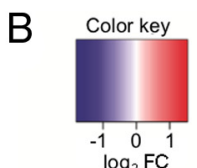

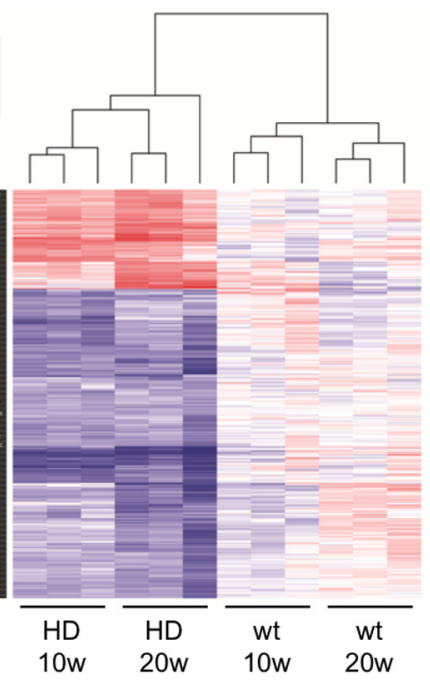

$\mathrm{F}$

Down

Up

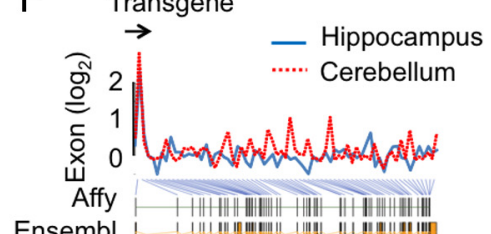

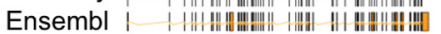

Figure 3. Transcriptional dysregulation in the hippocampus and cerebellum of HD82Q mice. $A$, The time points for RNA and chromatin samples collection are indicated along with a schematic representation of the progression of neuropathological traits and presence of $\mathrm{mHtt}$ aggregates. $\boldsymbol{B}$, Heatmap showing the $436 \mathrm{TC}$ IDs showing a significant genotype effect. $\boldsymbol{C}$, Scatter plot showing the FC ( $\log 2)$ of differentially expressed transcripts in the hippocampus of 10- and 20-week-old HD82Q mice. Note the deviation from the diagonal indicating that the progression of the pathology was associated with a slight worsening of the transcriptional deficits. This deviation was more prominent among upregulated TC IDs. D, Venn diagram showing the number of significant TC IDs retrieved in the contrast tests for 10- and 20-week-old mice (six arrays each). $\boldsymbol{E}$, Distribution of differentially expressed genes in hippocampus and cerebellum. The areas are proportional to the number of genes affected in each tissue and the percentage values correspond to the areas under the curve. $\boldsymbol{F}$, The analysis of individual probesets confirmed the overexpression of $H t t$ exon 1 in HD82Q samples. G, Validation and early onset of transcriptional deficits in hippocampus and cerebellum. RT-qPCR analysis of the temporal course of transcriptional dysregulation of selected genes retrieved in our differential screen. We confirmed the transcript level changes in both hippocampus (blue) and cerebellum (red) of HD820 mice. The discontinous line at Fold change 1 indicates the expression in wild-type littermates. In all panels, RNA samples were collected from 6-, 10-, and 20-week-old mice. Data are represented as the mean \pm SEM. Student's $t$ test $(p<0.05 ; p<0.005)$ : *, ** for pairwise comparisons. Two-way ANOVA $(p<0.05 ; p<0.005):+,++$ for genotype effect; \#, \#\# for age effect; $\S$ for genotype $x$ age interaction.

included activity-induced transcription factors (Nr4a1, Npas4) and BDNF isoforms. Our assays confirmed the downregulation of plasticity-related immediate early genes (IEG) in HD82Q mice and revealed that the two main activity-regulated promoters of $B d n f, \mathrm{P}-\mathrm{I}$, and P-IV, were both affected by HD pathology. In agreement with array data, the transcriptional deficits were, in general, more severe in cerebellar tissue. Overall, these experiments validated the microarray screen, confirmed the modest progression of transcriptional defects (only Gabrd, Npas4, and Nfya showed a significant progression with age), and demonstrated that transcriptional deficits in $\mathrm{HD} 82 \mathrm{Q}$ mice precede the onset of chorea and weight loss, which suggests a possible role for these alterations in the etiology of these symptoms.

\section{Hundreds of genomic loci are deacetylated in hippocampal} chromatin of HD82Q mice

To examine the relationship between transcriptional and epigenetic dysregulation associated with $\mathrm{mHtt}$ expression, we first assessed the level of acetylation of the four nucleosome histones by Western blotting and immunohistochemistry. In agreement with previous studies (Hockly et al., 2002; Sadri-Vakili et al., 2007; Klevytska et al., 2010; McFarland et al., 2012), but in contrast to others (Gardian et al., 2005; Stack et al., 2007; Giralt et al., 2012), neither one of these techniques revealed significant deficits in bulk chromatin of mHtt expressing tissues (Fig. 4).

We next used ChIPseq technology to tackle the identification of histone acetylation deficits with a resolution and genomic coverage 

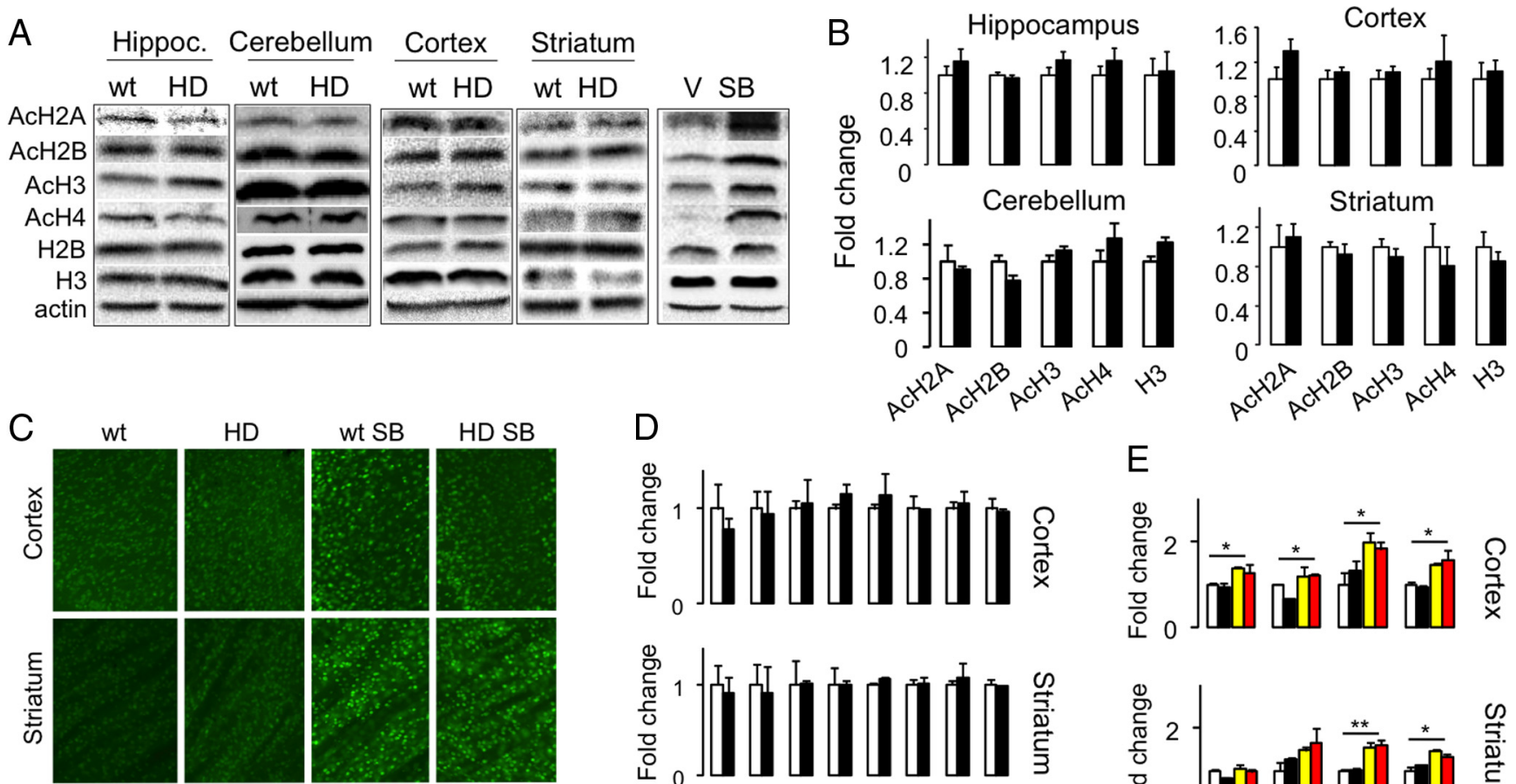
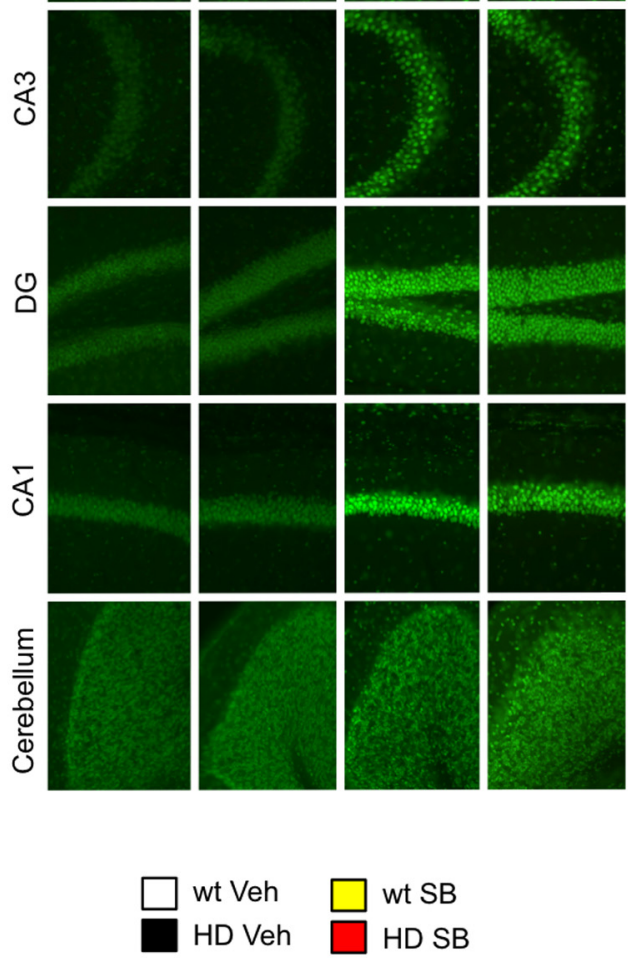
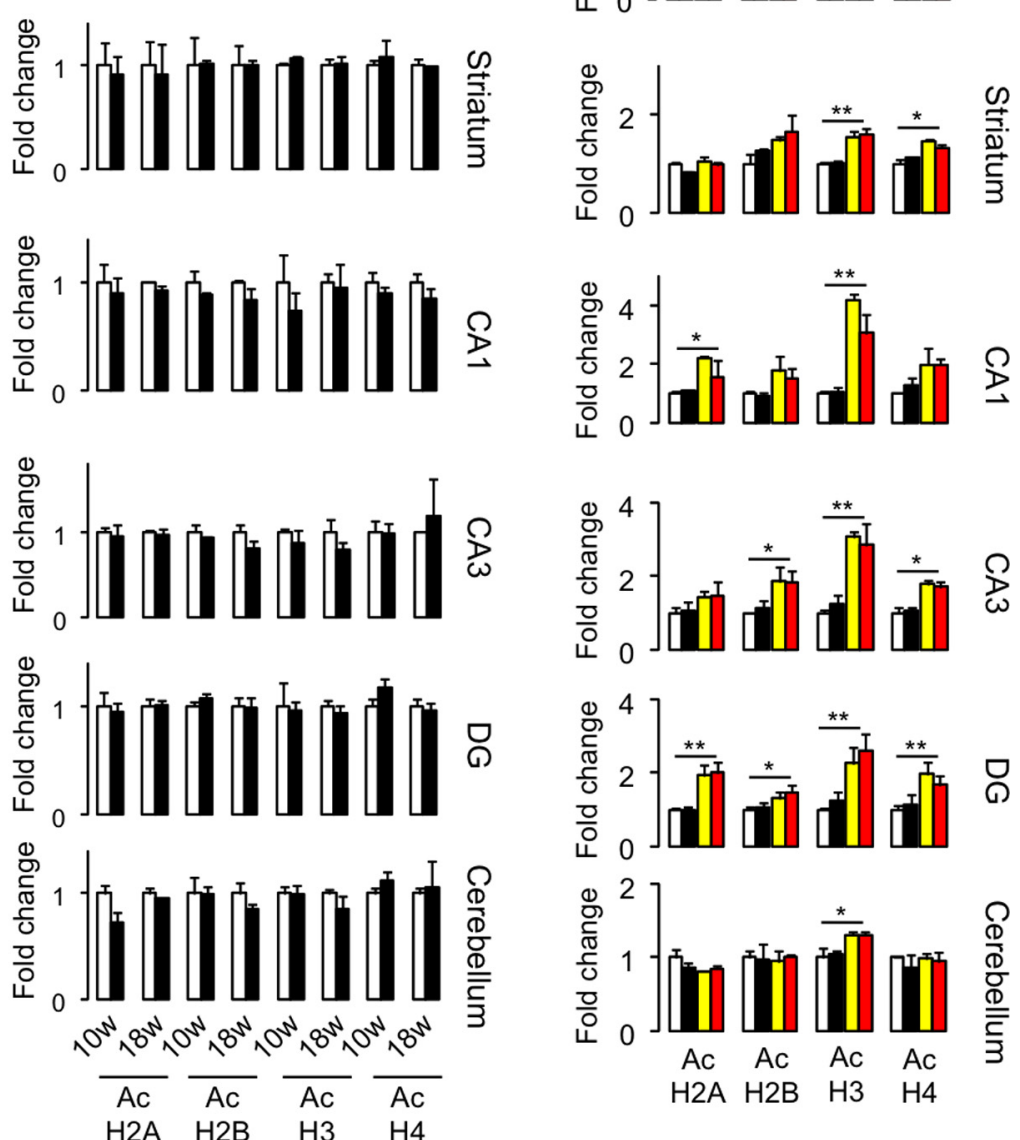
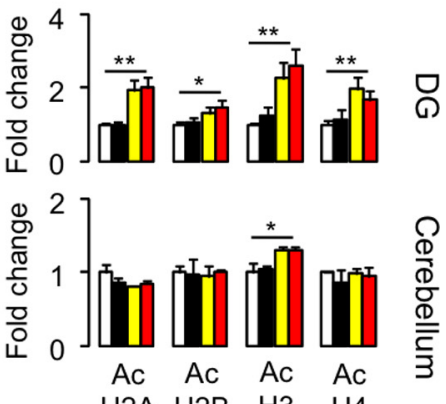

Figure 4. Bulk chromatin acetylation is not reduced in the brain of HD82Q mice. $A$, Representative Western blots analysis of hippocampal extracts from terminal HD820 (HD, 20-week-0ld) and wt littermate mice against different pan-acetylated histones. As a positive control, we also show histone acetylation levels in murine cortex after treatment with vehicle (V, PBS) or sodium butyrate (SB). B, Quantification of the Western blots. Hippocampus, striatum and cortex: $n=6$ (wt), $n=8$ (HD); cerebellum: $n=7$ (wt), $n=6$ (HD). C, Representative immunohistochemistry images of different brain areas from 18-week-old HD82Q (HD) and wt mice using an antibody against AcH3K9,14. Mice treated with SB were used as a positive control for the detection of significant changes in histone acetylation. This HDACi caused similar hyperacetylation of histones in HD82Q and wild-type littermates. Similar results were obtained for acetylated forms of the four nucleosome histones. Scale bar, $100 \mu \mathrm{m}$. D, Quantification of immunohistochemistry assays in 10- (10w) and 18-week-old (18w) mice; $n=4$ for both genotypes and times. $\boldsymbol{E}$, Quantification of immunohistochemistry assays in an independent set of HD82Q and wt littermate mice treated with vehicle or SB; $n=2$ per group; two-way ANOVA analysis did not reveal any genotype effect or genotype $x$ treatment interaction, but a significant HDACi treatment effect for different histones and brain areas. Data are represented as mean $\pm \mathrm{SEM}{ }^{*} p<0.05$; ${ }^{* *} p<0.005$ (tw0-way ANOVA, treatment effect).

that is unattainable through Western blot, locus-specific ChIP assays and ChIP-on-chip techniques. Given the relevance of the hippocampus in cognitive processes affected by $\mathrm{HD}$, we performed the ChIPseq screen in hippocampal chromatin of early symptomatic mice so that we could explore the predictive value of early deacety- lation in late transcriptional dysregulation. We focused on two relevant histone acetylation marks associated with active transcription: $\mathrm{AcH} 3 \mathrm{~K} 9,14$, which is regulated during memory processes (Levenson et al., 2004) and has been found reduced in some models of HD (Stack et al., 2007); and AcH4K12, which has been linked to age- 


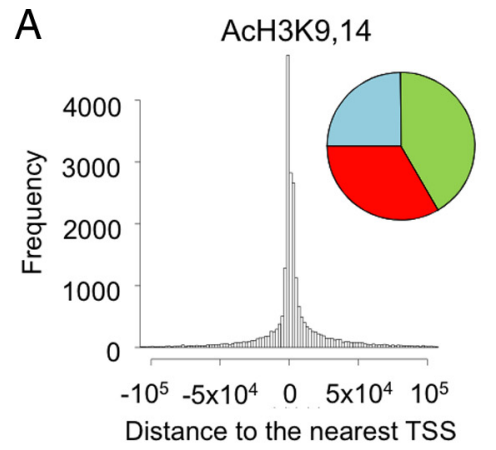

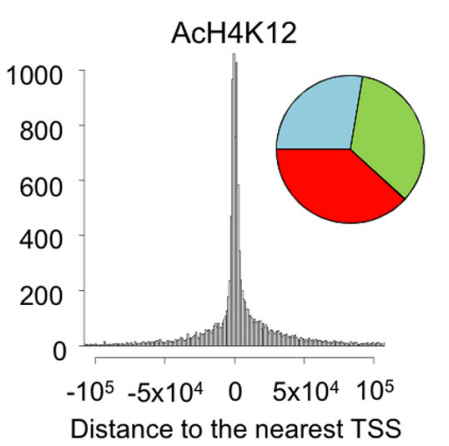

B AcH3K9,14

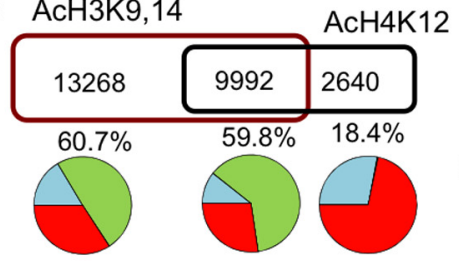

$\%$ of Max- $\mathrm{Q}_{3}$ genes with island

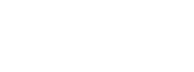

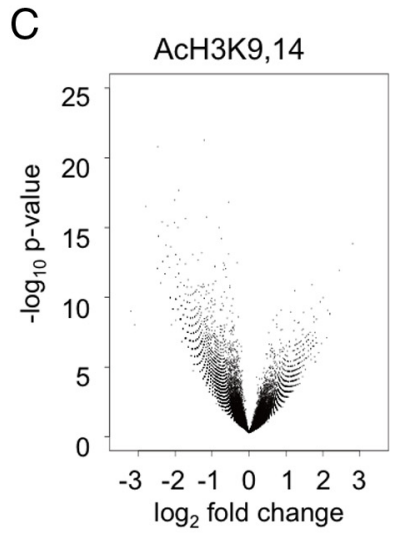

F

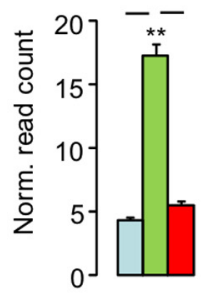

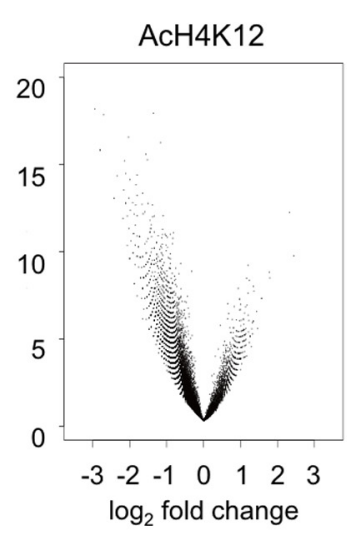

G
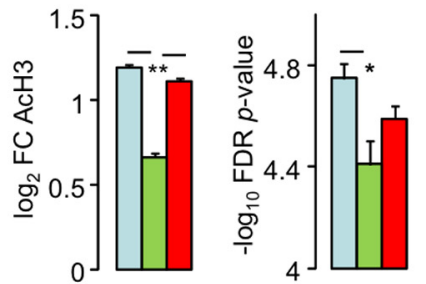

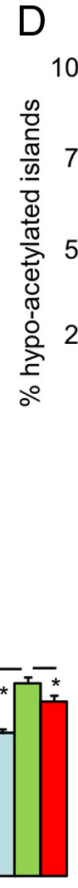

2156 out of 12632 islands $\mathrm{AcH} 4 \mathrm{~K} 12$

$\square$ Intergenic islands

$\square$ TSS islands

Intragenic and 3' end islands

Figure 5. Genomic topography of histone acetylation deficits in HD820 mice. $A$, Genomic distribution of ACH3K9,14 and ACH4K12 represented as frequencies of reads referred to the nearest TSS (frequency graphs) and percentages of islands located in different gene features (sector graphs): green, overlapping with TSS (including islands comprising the whole gene); red intragenic islands (inside exons or introns) and islands overlapping with the $3^{\prime}$-end; blue, intergenic islands (upstream and downstream of genes). $\boldsymbol{B}$, Venn diagram showing the physical overlap between AcH3K9,14 and AcH4K12 islands. The percentages indicate the proportion of genes associated with these islands that were highly expressed in the hippocampus (top $25 \%$, between the maximum and $Q_{3}$ values). The sector graphs show the distribution of these islands according to gene feature. The coloring is the same as in $A$. C, Volcano plots demonstrate the hypoacetylation of many enrichment islands in HD82Q samples for both marks. Note the asymmetric distribution of dots toward the left half of the graphs, which corresponds to negative $\log _{2}$ fold-change values. The outlier dots corresponding to the promoter region of Prnp (which is present in high copy number as part of the transgene) fall beyond the scale of the plot. $D$, Percentage of hypoacetylated islands according to their associated FDR $p$ value in the genotype comparison. Yellow lines label the significance threshold (FDR $p<10^{-3}$ ) used in all subsequent analyses. $E$, Percentage of effective genome size (i.e., excluding centromeric regions) occupied by the indicated acetylation marks. $\boldsymbol{F}, \boldsymbol{G}$, Normalized read count in control animals (left), magnitude (fold-change in absolute log 2 value) and significance $\left(-\log _{10}\right.$ FDRP $P$ value) of differentially acetylated H3K9,14 $(\boldsymbol{F})$ and H4K12 (G) islands in HD820 chromatin distributed according to their location referred to the nearest gene. Note that one island may fall in more than one category. $\boldsymbol{H}, \boldsymbol{I}$, Only a small percentage of genes showed significant changes at the TSS for the AcH3K9,14 $(\boldsymbol{H})$ and AcH4K12 (I) marks according to our filtering criteria.

related memory impairment (Peleg et al., 2010). The SICER algorithm, which is particularly suitable for identifying local enrichments for histone post-translational modifications (Zang et al., 2009), was used to identify acetylation-enriched chromatin regions. We found that both acetylation marks tended to accumulate in the proximity of the TSS (Fig. 5A) defining thousands of enrichment islands, most of which were located at promoters and intragenic sequences. The physical overlap between the two labels was high and revealed their convergence at active loci (Fig. 5B). Notably, there was a dramatic reduction in the number of islands detected in HD82Q chromatin compared with control samples (criterion FDR $p<10^{-8} ; 27.7 \%$ reduction for $\mathrm{AcH} 3 \mathrm{~K} 9,14$ and $71.7 \%$ reduction for $\mathrm{AcH} 4 \mathrm{~K} 12$ ).

SICER also allows the direct comparison of acetylation profiles between genotypes. The comparison revealed a general reduction of hippocampal chromatin acetylation in HD82Q mice that was especially severe for the AcH4K12 mark (Fig. 5C). To retrieve the most prominent changes, we set an arbitrary threshold (FDR $p<10^{-3}$ ) that identified $1560 \mathrm{AcH} 3 \mathrm{~K} 9,14$ islands and 2156 AcH4K12 islands altered by mHtt expression (Fig. 5D). Notably, the top ranked islands for both histone marks mapped onto the promoter of the prion protein gene (result not shown). Because this sequence is part of the HD82Q transgene and thereby it is in high copy number in the chromatin of mutant mice, their prominent position in the lists of differential islands represented a first validation of our differential screen. The great majority of the acetylation changes that passed our filtering criteria corresponded to hypoacetylation in HD82Q chromatin (87.7 and $96.9 \%$ of the islands for AcH3K9,14 and AcH4K12, respectively). As a whole, these differentially acetylated islands accounted for a small proportion $(<0.5 \%)$ of the murine genome 


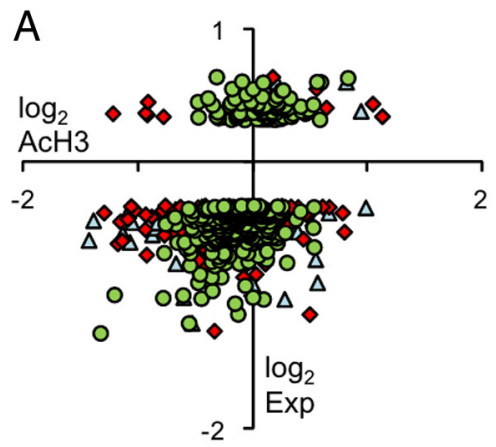

\begin{tabular}{|c|c|c|}
\hline Island loc. & $\mathbf{r}$ & genes \\
\hline Intergenic & 0.30 & 72 \\
\hline TSS & 0.47 & 328 \\
\hline Intra+3'end & 0.16 & 156 \\
\hline
\end{tabular}

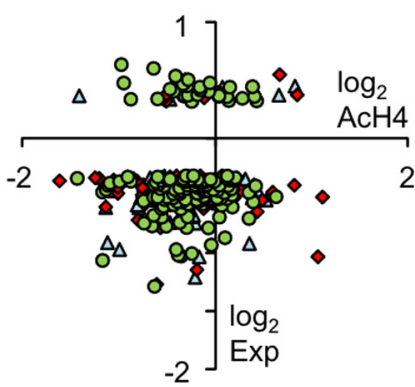

\begin{tabular}{|l|c|c|}
\hline Island loc. & $\mathbf{r}$ & genes \\
\hline Intergenic & 0.18 & 55 \\
\hline TSS & 0.07 & 147 \\
\hline Intragenic & 0.10 & 118 \\
\hline
\end{tabular}

B
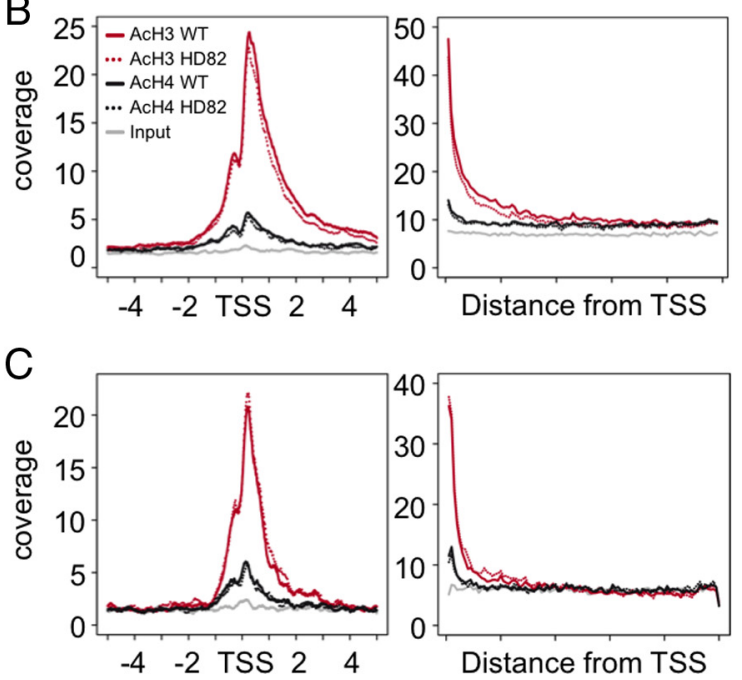

Figure 6. Correlation between gene expression and histone acetylation deficits. A, Correlation between fold changes in gene expression and histone acetylation profiles among differentially expressed genes (r, Pearson coefficient). The correlation for the AcH3 mark (left) was better considering those genes with TSS islands (green circles) compared with those located on intragenic (red diamonds) or intergenic (blue triangles) regions. No correlation was observed for the AcH4K12 mark in any subgroup of genes (right). $B, C$, Mean enrichment profiles presenting the genomic distribution of reads for ACH3K9,14 and AcH4K12 across the TSSs (left) and gene length (right) for genes down- $(\boldsymbol{B})$ or upregulated ( $\boldsymbol{C}$ ) in HD820 mice according to our array screen.

(Fig. 5E), which is consistent with the absence of significant changes in the acetylation of bulk chromatin reported above.

Most of these differentially acetylated islands mapped onto inter- and intragenic regions. Moreover, although the islands that overlapped with a TSS were in general larger than those located in inter- and intragenic regions, $\mathrm{mHtt}$-induced deacetylation at TSSs was less prominent and had lower statistical significance, particularly in the case of AcH3K9,14 (Fig. $5 F, G$ ). Overall, the changes at the TSS affected 2.6\% of AcH3K9,14 islands (Fig. $5 \mathrm{H}$ ) and $13.6 \%$ of AcH4K12 islands (Fig. 5I).

\section{Transcriptional and histone acetylation defects show low global correlation}

To investigate the correlation between ChIPseq and microarrays data, we discriminated between islands located in the TSS or in intra- and intergenic regions because we reasoned that islands at these different locations could distinctly contribute to transcription. The most prominent $\mathrm{H} 3 \mathrm{~K} 9,14$ and $\mathrm{H} 4 \mathrm{~K} 12$ acetylation changes detected in our ChIPseq screen showed no correlation with expression changes of the nearest gene (Pearson correlation indexes: $\left.r_{\text {TSS }}=0.17 ; r_{\text {Intragenic }}=0.03 ; r_{\text {Intergenic }}=0.04\right)$. In contrast, when we compared the genes significantly altered at the transcript level (genotype main effect, adjusted $p<0.05$ ) with nonfiltered fold-change values for the nearest $\mathrm{H} 3 \mathrm{~K} 9,14$ and H4K12 acetylation islands, a moderate correlation was observed in the case of AcH3K9, 14 islands located at the TSS ( $r=0.47$; Fig. $6 A)$. Consistently with these results, we observed a slight reduction or increase of acetylation levels at the TSS in HD82Q samples, respectively for down- or upregulated genes (Fig. $6 B, C$ ).

Genes showing both transcriptional and deacetylation defects are part of a consistent HD gene signature

Only 42 genes exhibited both a significantly reduction of transcript levels and $\mathrm{H} 3 \mathrm{~K} 9,14$ deacetylation at the TSS according to our filtering criteria (Fig. 7A). This gene set, thereafter referred as Exp-AcH3, showed a good correlation between the changes in gene expression and acetylation (Fig. $7 B ; r=0.69$ ). Independent RT-qPCR and ChIP-qPCR assays confirmed this association. In particular, we examined the loci encoding enkephalin, the mod- ulator of Ras signaling Rin1 and the regulator of dendritic growth Itpka (Fig. 7C). Additional ChIP-qPCR assays were performed at the TSS region of two candidate genes, the regulator of neuritic growth Plk5 (de Cárcer et al., 2011) and the epilepsy-related gene Gabrd (Dibbens et al., 2004), that were affected in both cerebellum and hippocampus (Fig. 7D). The assays demonstrated that the deacetylation of H3K9,14 detected in our ChIPseq experiment in the hippocampus also occurs in cerebellar chromatin. However, as reported above, the changes in gene expression and promoter acetylation did not always run in parallel. Thus, the promoter region of the gene encoding the activity-regulated cytoskeleton-associated (Arc) protein, which is downregulated in HD82Q samples, did not show any apparent change at the acetylation level (Fig. $7 E$ ).

We also investigated whether the genes exhibiting altered transcript levels specifically in the cerebellum were associated with $\mathrm{H} 3 \mathrm{~K} 9,14$ deacetylation of the promoter. We assessed the promoters of the cerebellar ataxia-associated gene Igfbp5 (Gatchel et al., 2008), the transcription factor Eomes (also known as $T b r 2$ ), the IEG Fos, and the substrate of protein kinase $\mathrm{C}$ Marcks (Fig. 7F). Like in the hippocampus, these gene specific assays confirmed the association of histone deacetylation events at TSS with relevant transcriptional deficits in HD tissue, but also indicated that additional epigenetic marks or mechanisms are required for explaining the full range of transcriptional alterations in polyQ disease as exemplified by Marcks.

To further investigate the relevance of the group of genes that exhibited concurrent changes in histone acetylation and gene expression in the hippocampus, we performed a GO enrichment analysis for this gene set and found a significant enrichment for ion binding proteins, particularly $\mathrm{Ca}^{2+}$-binding proteins, and components of the synapse (Fig. $7 G$ ), which is consistent with the important synaptic dysfunction reported for these mice (Li et al., 2003). We also asked whether the same genes were altered in other tissues and HD models. To address this question, we examined the datasets corresponding to cerebellar gene expression in HD82Q mice, to striatal gene expression in R6/2 mice (a mouse model of early onset HD that exhibits striatal degeneration; Kuhn et al., 2007) and to postmortem caudate nucleus from HD patients (Hodges et al., 2006). GO and 

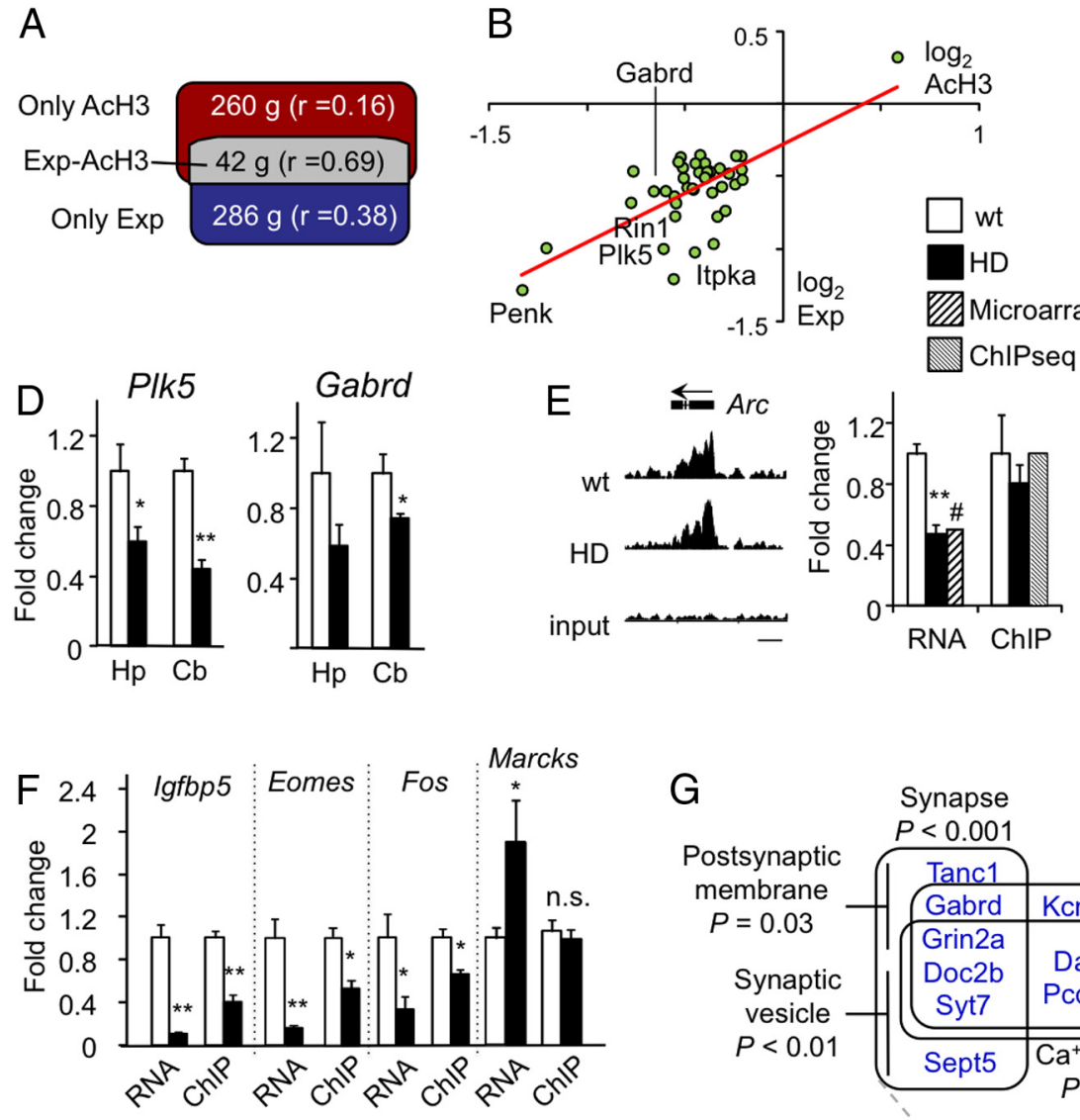

G

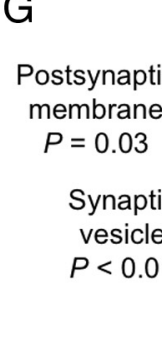

Synapse

Synapse
$P<0.001$
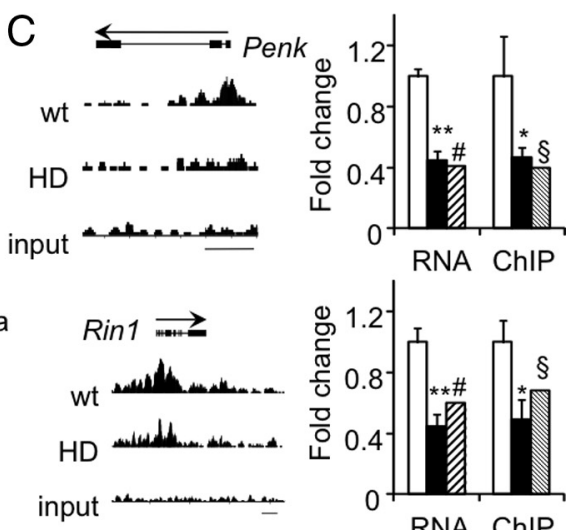

RNA ChIP

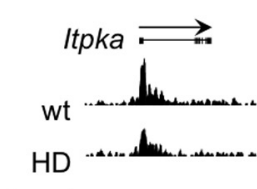

input

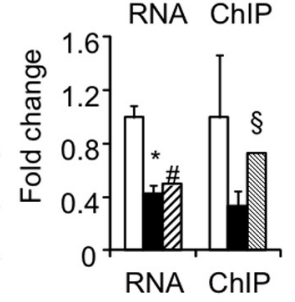

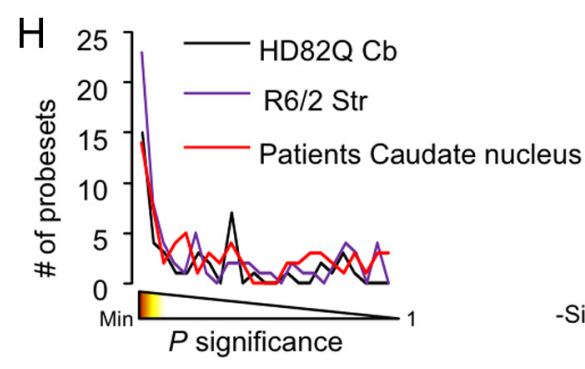

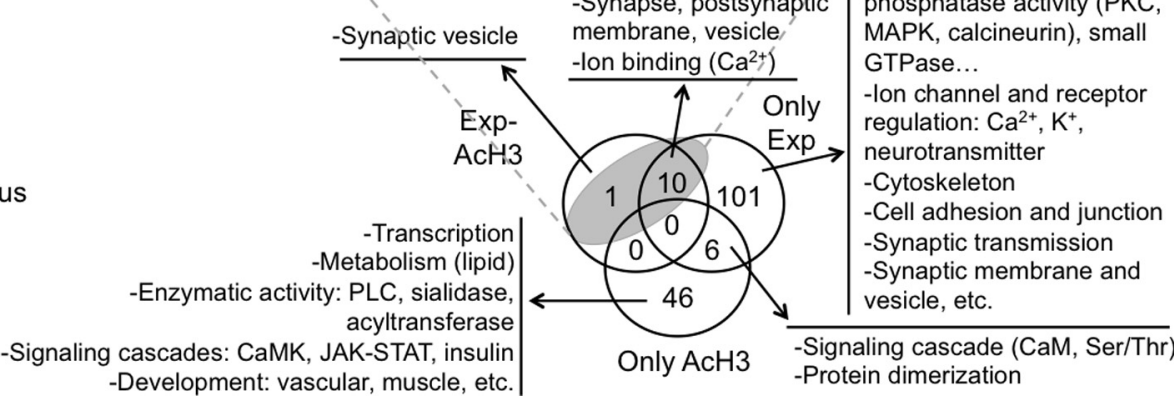

Figure 7. Genes showing both transcriptional and deacetylation defects are part of a consistent HD gene signature. $\boldsymbol{A}$, Venn diagram shows the overlapping between the genes differentially expressed and the genes differentially acetylated at the TSS. B, Correlation graph for the Exp-AcH3 subset. C, Bar graphs: ChIP-qPCR at the TSS of the genes Penk, Rin 1, and Itpka and parallel RT-qPCR assays for the corresponding transcripts validated ChIPseq and microarray experiments ( $n=5$ for wt and $n=6$ for HD82Q; results from 10-and 20-week-old mice were pooled). ChIPseq profiles are presented at the left of the bar graph for the same gene. Each region is depicted by the accumulation of reads around the $5^{\prime}$-end of the gene. Scale bar, $2 \mathrm{~kb}$. Data are presented as the mean \pm SEM. Comparisons refer to wt control: ${ }^{*} p<0.05$ and ${ }^{* *} p<0.005$ (Student's $t$ test); \#, $p<0.05$ (adjusted $p$ value in LIMMA analysis); $\S, p<10^{-3}$ (FDR $p$ value in SICER analysis). $\boldsymbol{D}$, ChIP-qPCR assays using AcH3K9,14 antibody were performed with cerebellar ( $\mathrm{Cb}, n=3$ for both genotypes) and hippocampal ( $\mathrm{Hp}, n=5$ for wt and $n=6$ for HD820) chromatin on the promoter of genes that were differently expressed in both brain areas. Comparisons refer to wt control: ${ }^{*} p<0.05 ;{ }^{* *} p<0.005$ (Student's $t$ test). E, Dissociation of transcript downregulation and promoter deacetylation for the gene Arc. Samples and legends are the same than for $\boldsymbol{C}$. F, ChIP-qPCR assays using AcH3K9,14 antibody were performed with cerebellar (Cb, $n=3$ for both genotypes) chromatin on the promoter of genes showing cerebellum-specific transcript changes. Data are represented as the mean $\pm \mathrm{SEM}^{*} p<0.05$ and ${ }^{* *} p<0.005$ (Student's $t$ test). $\mathbf{G}$, Venn diagram shows the number and overlap of significantly enriched G0 terms (in the categories of "Biological process", "Molecular function", and "Cellular component") in the subsets of genes retrieved in $A$ : genes that only exhibit changes in expression (Only Exp), only changes in H3K9,14 acetylation at the TSS (Only AcH3) or significant changes in both expression and TSS acetylation (Exp-AcH3, gray). A more detailed summary of the $\mathrm{GO}$ terms for the Exp-AcH3 subset is also depicted; blue, downregulated; red, upregulated. $\boldsymbol{H}$, Distribution of the TC IDs/probesets corresponding to Exp-AcH3 genes in the differential expression profiles obtained in the cerebellum of HD82Q mice $\left(\chi^{2}=124, \mathrm{df}=22, p<10^{-5}\right)$, the striatum of R6/2 mice $\left(\chi^{2}=176, \mathrm{df}=23, p<10^{-5}\right)$, and the caudate nucleus of $\mathrm{HD}$ patients $\left(\chi^{2}=67, \mathrm{df}=22, p<10^{-5}\right) \cdot \chi^{2}$ values are referred to a random distribution.

KEGG pathways enrichment analyses also revealed a large overlap between these the four datasets. More than $50 \%$ of the biological processes affected in the hippocampus were also enriched in the other datasets, including terms related to behavior (learning, memory, fear response), synaptic transmission, signaling pathways (phosphorylation, cAMP, small GTPase), and ion transport (mainly $\mathrm{K}^{+}$). The KEGG pathways calcium signaling, gap junction, MAPK signaling, and neuroactive ligand-receptor interaction were affected in all the examined datasets. In the three cases, we observed a highly significant enrichment for Exp-AcH3 probesets among the top ranked changes (Fig. $7 H$ ).

Interestingly, we also observed a good correlation between the enrichment for TFBS in the promoter of deacetylated genes and that in downregulated genes for the different HD models (Fig. 8A). Furthermore, downregulated genes showed high correlation indexes between all the gene profiles whereas upregulated genes were poorly 

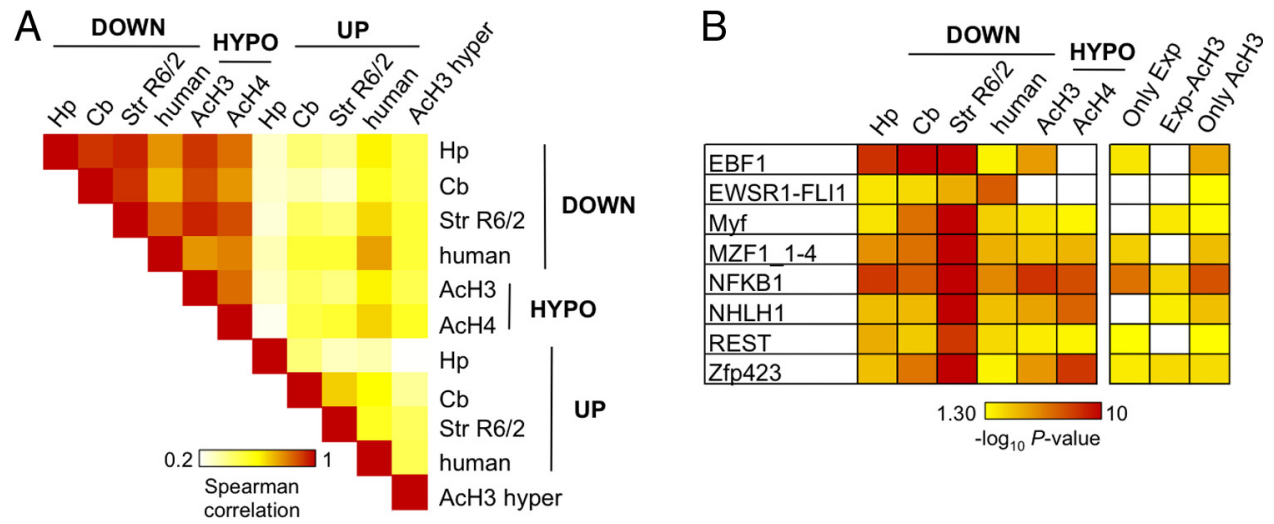

Figure 8. Functional genomics identifies transcriptional activities affected by $\mathrm{mHtt}$. $A$, Spearman correlation coefficients for TFBS enrichment in each dataset pair are presented as a heatmap. We compared the gene lists corresponding to significantly altered transcripts in HD82Q hippocampus (Hp) and cerebellum (Cb), R6/2 striatum (Str R6/2), caudate nucleus of HD patients (human) and hypo- and hyperacetylated TSS retrieved in our ChIPseq screen in HD82Q hippocampus. A good correlation was observed between the enrichment for TFBSs in the promoter of deacetylated genes (HYPO) and that in downregulated genes (DOWN) for the different HD models. In contrast, the enrichment in hyperacetylated genes (HYPER, only shown for AcH3K9,14 given the rarity of H4K12 hyperacetylation events) did not correlate with that in upregulated genes (UP). $\boldsymbol{B}$, Heatmap presenting the significance of TFBS enrichment for motifs that were consistently retrieved in the analysis of downregulated genes in the different expression profiles described above. The significance of the enrichment for the same TFBSs in the three gene sets defined in Figure $7 \mathrm{~A}$ is also shown. The color palette indicates the $P$ value range; white: nonsignificant $(P>0.05)$.

correlated. Together, these results suggest that common transcriptional mechanisms might be involved in the aberrant gene downregulation and deacetylation, whereas homeostatic responses (which are likely to contribute more prominently to gene upregulations) might depend on tissue-specific mechanisms. Among the most significant and consistent motifs detected in this meta-analysis were the binding sites of NRSF/REST and NF- $\kappa$ B that have both been previously involved in HD (Buckley et al., 2010; Marcora and Kennedy, 2010; Ravache et al., 2010; Datta and Bhattacharyya, 2011) (Fig. $8 B$ ). This analysis (limited to the motifs represented in the Jaspar database) did not identify DNA motifs unique to the Exp$\mathrm{AcH} 3$ subset and that could thereby establish a specific link histone acetylation and gene expression deficits.

\section{Discussion}

\section{Genomic landscape of transcriptional and epigenetic} dysregulation in polyQ disease

Distinctive clinical features and brain imaging studies suggest that hippocampal and cerebellar malfunction may be especially relevant in early onset HD, an aggressive form of the disease associated with very long CAG repeats (Rodda, 1981; Rosas et al., 2003; Seneca et al., 2004; Paradiso et al., 2008; Ruocco et al., 2008). Moreover, other polyQ pathologies, such as different types of spinocerebellar ataxias, have the cerebellum as the main target (Orr and Zoghbi, 2007; Seidel et al., 2012). The regional pattern of transgene expression and the severity and fast progression of neuropathological traits in HD82Q mice made this strain especially suitable for investigating early onset polyQ pathology in these structures.

Our experiments demonstrate that the acetylation deficits observed in HD82Q mice are not global but are restricted to specific loci and associated with specific TFBS and genomic features. Although the two acetylation marks explored here have been linked to active loci, their profiles revealed remarkable differences. The enrichment profile of $\mathrm{AcH} 3 \mathrm{~K} 9,14$ showed sharp peaks that overlapped with the TSS, whereas AcH4K12 enrichment was characterized by wider and blunter islands that frequently occupied intra- and intergenic regions. The impact of HD pathology on the two profiles was also different. Although deacetylation of AcH4K12 islands in HD82Q chromatin was more severe than that of $\mathrm{AcH} 3 \mathrm{~K} 9,14$ islands, these changes were not associated with significant transcriptional deficits. As a result, we observed a much better correlation between reduced transcript levels and deacetylation at the TSS for AcH3K9, 14 than for AcH4K12. Importantly, deregulated H4K12 acetylation has been also observed in the aging mouse hippocampus and linked to age-related memory impairment (Peleg et al., 2010). Our data therefore support the notion that neuronal H4K12 deacetylation may represent a biomarker for epigenetic dysregulation associated with hippocampal malfunction or degeneration, although the specific role of this mark in gene expression remains unknown.

\section{Are histone acetylation and transcriptional dysregulation two} independent manifestations of polyQ pathology?

Our appreciation of the complexity of epigenetic regulation of gene expression has dramatically increased with the development of new genomic techniques based on next generation sequencing (Dawson and Kouzarides, 2012). The novel insight that emerged from these studies has challenged many assumptions regarding the role of histone modifications in gene expression (Strahl and Allis, 2000; Schübeler et al., 2004; Wang et al., 2008) and basic questions, such as whether the transcriptional rate of a locus is determined by its histone acetylation level or vice versa, are now under debate (Henikoff and Shilatifard, 2011; Bedford and Brindle, 2012). One of the most striking conclusions of our comprehensive analysis is that histone deacetylation and transcriptional defects were, in general, not linked. This result is in good agreement with studies in yeast, flies, and mouse fibroblasts showing that the post-translational modification of histones may not be as essential for gene expression as anticipated. Thus, whole-genome analyses of gene expression changes in histone mutants have typically revealed modest phenotypes and relatively little phenotypic complexity resulting from the combination of histone mutations (Lenstra et al., 2011; Rando, 2012).

In agreement with a recent report based on a chip-on-chip screen (McFarland et al., 2012), our correlative analyses demonstrated an important mismatch between gene dysregulation and histone deacetylation in polyQ disorders, which indicates that the relationship between these two phenomena is more complex than anticipated (Saha and Pahan, 2006; Stack et al., 2007). With the exception of some H3K9,14 acetylation deficits located at TSS of genes that were part of a consistent signature found in different HD datasets, most of the differences in histone acetylation de- 
tected in our differential screen mapped onto inter- and intragenic regions. Moreover, deacetylation events in inter- and intragenic regions were in average more prominent than those in TSSs. These acetylation defects did not have an apparent direct impact on the expression of the nearest gene. However, we still do not know the meaning of deacetylation events outside of the well studied protein-coding regions (Bernstein et al., 2012). For instance, a correlation between histone deacetylation at intergenic regions and noncoding RNA transcription (which are underrepresented in current microarrays) might still exist. These defects could also have trans and long-distance effects in other loci (Sanyal et al., 2012) or interfere with the transcriptional response of the cell to future challenges or insults. In fact, genes that are activated in response to stimuli, such as $B d n f$ (isoforms I and IV), the IEGs Arc, Nr4al, and Npas4 and others activity-regulated genes, were especially affected at the transcriptional level.

On the other hand, although we may have underestimated the number of genes that show a positive correlation between histone deacetylation and transcript downregulation due to the stringent filters used in our screen, the majority of the genes with reduced transcript levels in HD82Q samples did not exhibit significant changes in the two investigated acetylation marks. Therefore, other mechanisms, such as other post-translational modifications of histone (Kim et al., 2008), aberrant DNA methylation (Ng et al., 2013), and altered TF activities (Yamanaka et al., 2008; Buckley et al., 2010; Marcora and Kennedy, 2010; Ravache et al., 2010; Datta and Bhattacharyya, 2011), should also contribute to transcriptional dysregulation in HD. Because the compromised lysine acetyltransferase activity observed in the brain of HD82Q mice may also affect nonhistone substrates (Dompierre et al., 2007), including TFs like NF- $\kappa$ B whose activity is regulated by acetylation (Zhang et al., 2010), the histone deacetylation-independent transcriptional dysregulation may still be deacetylation-dependent. Consistently with this view, NF- $\kappa$ B binding sites were enriched in the promoters of both downregulated and deacetylated genes.

In conclusion, the combination of ChIPseq and microarray technologies supported the hypothesis that transcriptional and epigenetic dysregulation, particularly aberrant acetylation of neuronal chromatin, are early features of polyQ pathology. However, our results suggest that these are two largely independent manifestations of the pathology. Our screen also identified a relatively small subset of candidate genes that show potential as progression biomarkers or therapeutic targets for this fatal neurodegenerative disease. These results lead to new questions, such as how the expression of $\mathrm{mHtt}$ drives deacetylation to specific genomic regions and what causes the transcriptional deficits that were not associated with histone deacetylation. Regardless of the answers to those important questions, high-resolution description of the genomic topography of epigenetic and transcriptional alterations appears to be an essential requirement for a better understanding of the etiology of polyQ diseases and for the development of effective therapies aimed at correcting the deficits.

\section{Notes}

Supplemental material for this article is available at http://in.umh. es/IP/Barco-lab-DataSets.html. Access to: Tables that present the results of microarrays and ChIPseq differential screenings. This material has not been peer reviewed.

\section{References}

Bedford DC, Brindle PK (2012) Is histone acetylation the most important physiological function for CBP and p300? Aging 4:247-255. Medline

Bernstein BE, et al. (2012) An integrated encyclopedia of DNA elements in the human genome. Nature 489:57-74. CrossRef Medline
Bowles KR, Brooks SP, Dunnett SB, Jones L (2012) Gene expression and behaviour in mouse models of HD. Brain Res Bull 88:276-284. CrossRef Medline

Buckley NJ, Johnson R, Zuccato C, Bithell A, Cattaneo E (2010) The role of REST in transcriptional and epigenetic dysregulation in Huntington's disease. Neurobiol Dis 39:28-39. CrossRef Medline

Cha JH (2000) Transcriptional dysregulation in Huntington's disease. Trends Neurosci 23:387-392. CrossRef Medline

Datta M, Bhattacharyya NP (2011) Regulation of RE1 protein silencing transcription factor (REST) expression by HIP1 protein interactor (HIPPI). J Biol Chem 286:33759-33769. CrossRef Medline

Dawson MA, Kouzarides T (2012) Cancer epigenetics: from mechanism to therapy. Cell 150:12-27. CrossRef Medline

de Cárcer G, Escobar B, Higuero AM, García L, Ansón A, Pérez G, Mollejo M, Manning G, Meléndez B, Abad-Rodríguez J, Malumbres M (2011) Plk5, a polo box domain-only protein with specific roles in neuron differentiation and glioblastoma suppression. Mol Cell Biol 31:1225-1239. CrossRef Medline

Dibbens LM, Feng HJ, Richards MC, Harkin LA, Hodgson BL, Scott D, Jenkins M, Petrou S, Sutherland GR, Scheffer IE, Berkovic SF, Macdonald RL, Mulley JC (2004) GABRD encoding a protein for extra- or perisynaptic GABAA receptors is a susceptibility locus for generalized epilepsies. Hum Mol Genet 13:1315-1319. CrossRef Medline

Dompierre JP, Godin JD, Charrin BC, Cordelières FP, King SJ, Humbert S, Saudou F (2007) Histone deacetylase 6 inhibition compensates for the transport deficit in Huntington's disease by increasing tubulin acetylation. J Neurosci 27:3571-3583. CrossRef Medline

Gardian G, Browne SE, Choi DK, Klivenyi P, Gregorio J, Kubilus JK, Ryu H, Langley B, Ratan RR, Ferrante RJ, Beal MF (2005) Neuroprotective effects of phenylbutyrate in the N171-82Q transgenic mouse model of Huntington's disease. J Biol Chem 280:556-563. CrossRef Medline

Gatchel JR, Watase K, Thaller C, Carson JP, Jafar-Nejad P, Shaw C, Zu T, Orr HT, Zoghbi HY (2008) The insulin-like growth factor pathway is altered in spinocerebellar ataxia type 1 and type 7. Proc Natl Acad Sci U S A 105:1291-1296. CrossRef Medline

Gentleman RC, Carey VJ, Bates DM, Bolstad B, Dettling M, Dudoit S, Ellis B, Gautier L, Ge Y, Gentry J, Hornik K, Hothorn T, Huber W, Iacus S, Irizarry R, Leisch F, Li C, Maechler M, Rossini AJ, Sawitzki G, Smith C, et al. (2004) Bioconductor: open software development for computational biology and bioinformatics. Genome Biol 5:R80. CrossRef Medline

Giralt A, Puigdellívol M, Carretón O, Paoletti P, Valero J, Parra-Damas A, Saura CA, Alberch J, Ginés S (2012) Long-term memory deficits in Huntington's disease are associated with reduced CBP histone acetylase activity. Hum Mol Genet 21:1203-1216. CrossRef Medline

HenikoffS, Shilatifard A (2011) Histone modification: cause or cog? Trends Genet 27:389-396. CrossRef Medline

Hockly E, Cordery PM, Woodman B, Mahal A, van Dellen A, Blakemore C, Lewis CM, Hannan AJ, Bates GP (2002) Environmental enrichment slows disease progression in R6/2 Huntington's disease mice. Ann Neurol 51:235-242. CrossRef Medline

Hodges A, Strand AD, Aragaki AK, Kuhn A, Sengstag T, Hughes G, Elliston LA, Hartog C, Goldstein DR, Thu D, Hollingsworth ZR, Collin F, Synek B, Holmans PA, Young AB, Wexler NS, Delorenzi M, Kooperberg C, Augood SJ, Faull RL, et al. (2006) Regional and cellular gene expression changes in human Huntington's disease brain. Hum Mol Genet 15:965-977. CrossRef Medline

Huang da W, Sherman BT, Lempicki RA (2009) Systematic and integrative analysis of large gene lists using DAVID bioinformatics resources. Nat Protoc 4:44-57. CrossRef Medline

Kim MO, Chawla P, Overland RP, Xia E, Sadri-Vakili G, Cha JH (2008) Altered histone monoubiquitylation mediated by mutant huntingtin induces transcriptional dysregulation. J Neurosci 28:3947-3957. CrossRef Medline

Klevytska AM, Tebbenkamp AT, Savonenko AV, Borchelt DR (2010) Partial depletion of CREB-binding protein reduces life expectancy in a mouse model of Huntington disease. J Neuropathol Exp Neurol 69:396-404. CrossRef Medline

Kuhn A, Goldstein DR, Hodges A, Strand AD, Sengstag T, Kooperberg C, Becanovic K, Pouladi MA, Sathasivam K, Cha JH, Hannan AJ, Hayden MR, Leavitt BR, Dunnett SB, Ferrante RJ, Albin R, Shelbourne P, Delorenzi M, Augood SJ, Faull RL, Olson JM, et al. (2007) Mutant huntingtin's effects on striatal gene expression in mice recapitulate changes observed in human 
Huntington's disease brain and do not differ with mutant huntingtin length or wild-type huntingtin dosage. Hum Mol Genet 16:1845-1861. CrossRef Medline

Lenstra TL, Benschop JJ, Kim T, Schulze JM, Brabers NA, Margaritis T, van de Pasch LA, van Heesch SA, Brok MO, Groot Koerkamp MJ, Ko CW, van Leenen D, Sameith K, van Hooff SR, Lijnzaad P, Kemmeren P, Hentrich T, Kobor MS, Buratowski S, Holstege FC (2011) The specificity and topology of chromatin interaction pathways in yeast. Mol Cell 42:536-549. CrossRef Medline

Levenson JM, O’Riordan KJ, Brown KD, Trinh MA, Molfese DL, Sweatt JD (2004) Regulation of histone acetylation during memory formation in the hippocampus. J Biol Chem 279:40545-40559. CrossRef Medline

Li H, Durbin R (2010) Fast and accurate long-read alignment with BurrowsWheeler transform. Bioinformatics 26:589-595. CrossRef Medline

Li H, Wyman T, Yu ZX, Li SH, Li XJ (2003) Abnormal association of mutant huntingtin with synaptic vesicles inhibits glutamate release. Hum Mol Genet 12:2021-2030. CrossRef Medline

Li H, Handsaker B, Wysoker A, Fennell T, Ruan J, Homer N, Marth G, Abecasis G, Durbin R (2009) The sequence alignment/map format and SAMtools. Bioinformatics 25:2078-2079. CrossRef Medline

Lopez de Armentia M, Jancic D, Olivares R, Alarcon JM, Kandel ER, Barco A (2007) cAMP response element-binding protein-mediated gene expression increases the intrinsic excitability of CA1 pyramidal neurons. J Neurosci 27:13909-13918. CrossRef Medline

Lopez-Atalaya JP, Ciccarelli A, Viosca J, Valor LM, Jimenez-Minchan M, Canals S, Giustetto M, Barco A (2011) CBP is required for environmental enrichment-induced neurogenesis and cognitive enhancement. EMBO J 30:4287-4298. CrossRef Medline

MacDonald ME, Ambrose CM, Duyao MP, Myers RH, Lin C, Srinidhi L, Barnes G, Taylor SA, James M, Groot N, MacFarlane H, Jenkins B, Anderson MA, Wexler NS, Gusella JF, Bates GP, Baxendale S, Hummerich H, Kirby S, North $\mathrm{M}$, et al. (1993) A novel gene containing a trinucleotide repeat that is expanded and unstable on Huntington's disease chromosomes. The Huntington's Disease Collaborative Research Group. Cell 72:971-983. CrossRef Medline

Marcora E, Kennedy MB (2010) The Huntington's disease mutation impairs Huntington's role in the transport of NF-kappaB from the synapse to the nucleus. Hum Mol Genet 19:4373-4384. CrossRef Medline

McFarland KN, Das S, Sun TT, Leyfer D, Xia E, Sangrey GR, Kuhn A, LuthiCarter R, Clark TW, Sadri-Vakili G, Cha JH (2012) Genome-wide histone acetylation is altered in a transgenic mouse model of Huntington's disease. PLoS ONE 7:e41423. CrossRef Medline

Ng CW, Yildirim F, Yap YS, Dalin S, Matthews BJ, Velez PJ, Labadorf A, Housman DE, Fraenkel E (2013) Extensive changes in DNA methylation are associated with expression of mutant huntingtin. Proc Natl Acad Sci U S A 110:2354-2359. CrossRef Medline

Oliveros J (2007) Venny: an interactive tool for comparing lists with Venn diagrams. http://bioinfogp.cnb.csic.es/tools/venny/index.html.

Orr HT, Zoghbi HY (2007) Trinucleotide repeat disorders. Annu Rev Neurosci 30:575-621. CrossRef Medline

Paradiso S, Turner BM, Paulsen JS, Jorge R, Ponto LL, Robinson RG (2008) Neural bases of dysphoria in early Huntington's disease. Psychiatry Res 162:73-87. CrossRef Medline

Peleg S, Sananbenesi F, Zovoilis A, Burkhardt S, Bahari-Javan S, Agis-Balboa RC, Cota P, Wittnam JL, Gogol-Doering A, Opitz L, Salinas-Riester G, Dettenhofer M, Kang H, Farinelli L, Chen W, Fischer A (2010) Altered histone acetylation is associated with age-dependent memory impairment in mice. Science 328:753-756. CrossRef Medline

Rando OJ (2012) Combinatorial complexity in chromatin structure and function: revisiting the histone code. Curr Opin Genet Dev 22:148-155. CrossRef Medline

Ravache M, Weber C, Mérienne K, Trottier Y (2010) Transcriptional activation of REST by Sp1 in Huntington's disease models. PLoS ONE 5:e14311. CrossRef Medline

Robinson JT, Thorvaldsdóttir H, Winckler W, Guttman M, Lander ES, Getz G, Mesirov JP (2011) Integrative genomics viewer. Nat Biotechnol 29:24-26. CrossRef Medline

Rodda RA (1981) Cerebellar atrophy in Huntington's disease. J Neurol Sci 50:147-157. CrossRef Medline

Rosas HD, Koroshetz WJ, Chen YI, Skeuse C, Vangel M, Cudkowicz ME, Caplan K, Marek K, Seidman LJ, Makris N, Jenkins BG, Goldstein JM (2003) Evidence for more widespread cerebral pathology in early HD: an
MRI-based morphometric analysis. Neurology 60:1615-1620. CrossRef Medline

Ruocco HH, Bonilha L, Li LM, Lopes-Cendes I, Cendes F (2008) Longitudinal analysis of regional grey matter loss in Huntington disease: effects of the length of the expanded CAG repeat. J Neurol Neurosurg Psychiatry 79:130 135. CrossRef Medline

Sadri-Vakili G, Bouzou B, Benn CL, Kim MO, Chawla P, Overland RP, Glajch KE, Xia E, Qiu Z, Hersch SM, Clark TW, Yohrling GJ, Cha JH (2007) Histones associated with downregulated genes are hypo-acetylated in Huntington's disease models. Hum Mol Genet 16:1293-1306. CrossRef Medline

Saha RN, Pahan K (2006) HATs and HDACs in neurodegeneration: a tale of disconcerted acetylation homeostasis. Cell Death Differ 13:539-550. CrossRef Medline

Sanchis-Segura C, Lopez-Atalaya JP, Barco A (2009) Selective boosting of transcriptional and behavioral responses to drugs of abuse by histone deacetylase inhibition. Neuropsychopharmacology 34:2642-2654. CrossRef Medline

Sanyal A, Lajoie BR, Jain G, Dekker J (2012) The long-range interaction landscape of gene promoters. Nature 489:109-113. CrossRef Medline

Schilling G, Becher MW, Sharp AH, Jinnah HA, Duan K, Kotzuk JA, Slunt HH, Ratovitski T, Cooper JK, Jenkins NA, Copeland NG, Price DL, Ross CA, Borchelt DR (1999) Intranuclear inclusions and neuritic aggregates in transgenic mice expressing a mutant $\mathrm{N}$-terminal fragment of huntingtin. Hum Mol Genet 8:397-407. CrossRef Medline

Schübeler D, MacAlpine DM, Scalzo D, Wirbelauer C, Kooperberg C, van Leeuwen F, Gottschling DE, O'Neill LP, Turner BM, Delrow J, Bell SP, Groudine M (2004) The histone modification pattern of active genes revealed through genome-wide chromatin analysis of a higher eukaryote. Genes Dev 18:1263-1271. CrossRef Medline

Seidel K, Siswanto S, Brunt ER, den Dunnen W, Korf HW, Rüb U (2012) Brain pathology of spinocerebellar ataxias. Acta Neuropathologica 124:1-21. CrossRef Medline

Seneca S, Fagnart D, Keymolen K, Lissens W, Hasaerts D, Debulpaep S, Desprechins B, Liebaers I, De Meirleir L (2004) Early onset Huntington disease: a neuronal degeneration syndrome. Eur J Pediatr 163:717-721. CrossRef Medline

Seredenina T, Luthi-Carter R (2012) What have we learned from gene expression profiles in Huntington's disease? Neurobiol Dis 45:83-98. CrossRef Medline

Smyth G (2005) Limma: linear models for microarray data. New York: Springer.

Snowden JS, Craufurd D, Thompson J, Neary D (2002) Psychomotor, executive, and memory function in preclinical Huntington's disease. J Clin Exp Neuropsychol 24:133-145. CrossRef Medline

Stack EC, Del Signore SJ, Luthi-Carter R, Soh BY, Goldstein DR, Matson S, Goodrich S, Markey AL, Cormier K, Hagerty SW, Smith K, Ryu H, Ferrante RJ (2007) Modulation of nucleosome dynamics in Huntington's disease. Hum Mol Genet 16:1164-1175. CrossRef Medline

Strahl BD, Allis CD (2000) The language of covalent histone modifications. Nature 403:41-45. CrossRef Medline

Valor LM, Pulopulos MM, Jimenez-Minchan M, Olivares R, Lutz B, Barco A (2011) Ablation of CBP in forebrain principal neurons causes modest memory and transcriptional defects and a dramatic reduction of histone acetylation, but does not affect cell viability. J Neurosci 31:1652-1663. CrossRef Medline

Valor LM, Viosca J, Lopez-Atalaya JP, Barco A (2013) Lysine acetyltransferases CBP and p300 as therapeutic targets in cognitive and neurodegenerative disorders. Curr Pharm Des. Advance online publication. Retrieved Feb. 19, 2013. doi:10.2174/13816128113199990382. CrossRef Medline

Wang Z, Zang C, Rosenfeld JA, Schones DE, Barski A, Cuddapah S, Cui K, Roh TY, Peng W, Zhang MQ, Zhao K (2008) Combinatorial patterns of histone acetylations and methylations in the human genome. Nat Genet 40:897-903. CrossRef Medline

Yamanaka T, Miyazaki H, Oyama F, Kurosawa M, Washizu C, Doi H, Nukina N (2008) Mutant huntingtin reduces HSP70 expression through the sequestration of NF-Y transcription factor. EMBO J 27:827-839. CrossRef Medline

Zambelli F, Pesole G, Pavesi G (2009) Pscan: finding over-represented transcription factor binding site motifs in sequences from co-regulated or coexpressed genes. Nucleic Acids Res 37:W247-252. CrossRef Medline

Zang C, Schones DE, Zeng C, Cui K, Zhao K, Peng W (2009) A clustering 
approach for identification of enriched domains from histone modification ChIP-seq data. Bioinformatics 25:1952-1958. CrossRef Medline

Zhang LX, Zhao Y, Cheng G, Guo TL, Chin YE, Liu PY, Zhao TC (2010) Targeted deletion of NF-kappaB p50 diminishes the cardioprotection of histone deacetylase inhibition. Am J Physiol Heart Circ Physiol 298: H2154-2163. CrossRef Medline
Zhu LJ, Gazin C, Lawson ND, Pagès H, Lin SM, Lapointe DS, Green MR (2010) ChIPpeakAnno: a bioconductor package to annotate ChIP-seq and ChIP-chip data. BMC Bioinformatics 11:237. CrossRef Medline

Zuccato C, Valenza M, Cattaneo E (2010) Molecular mechanisms and potential therapeutical targets in Huntington's disease. Physiological reviews 90:905-981. CrossRef Medline 